\title{
Comparison of Statistical and Analytical Hierarchy Process Methods on Flood Susceptibility Mapping: In a Case Study of the Tana Sub-basin in Northwestern Ethiopia
}

\author{
Azemeraw Wubalem ( $\nabla$ alubelw@gmail.com ) \\ 5965-6608

\section{Gashaw Tesfaw} \\ University of Gondar College of Natural and Computational Sciences

\section{Zerihun Dawit} \\ University of Gondar College of Natural and Computational Sciences

\section{Belete Getahun} \\ University of Gondar College of Natural and Computational Sciences

\section{Tamirat Mekuria} \\ University of Gondar College of Natural and Computational Sciences

\section{Muralitharan Jothimani} \\ University of Gondar College of Natural and Computational Sciences
}

University of Gondar College of Natural and Computational Sciences https://orcid.org/0000-0002-

\section{Research}

Keywords: flood, susceptibility, Geographic Information System (GIS), analytical hierarchy process (AHP), frequency ratio, information value, logistic regression, Ethiopia

Posted Date: February 3rd, 2021

DOI: https://doi.org/10.21203/rs.3.rs-154638/v1

License: (c) (i) This work is licensed under a Creative Commons Attribution 4.0 International License.

Read Full License

Version of Record: A version of this preprint was published at Open Geosciences on January 1st, 2021.

See the published version at https://doi.org/10.1515/geo-2020-0329. 


\title{
Comparison of statistical and analytical hierarchy process methods on flood susceptibility mapping: in a case study of the Tana sub-basin in northwestern Ethiopia
}

\author{
Azemeraw Wubalem*1, Gashaw Tesfaw ${ }^{1}$, Zerihun Dawit ${ }^{1}$, Belete Getahun ${ }^{1}$, Tamirat Mekuria ${ }^{1}$, \\ Muralitharan Jothimani ${ }^{1}$ \\ 1. Department of Geology, College of Natural and Computational Sciences, University of Gondar, Ethiopia, P.X.BOX \\ 196
}

\begin{abstract}
The sub-basin of Lake Tana is one of the most flood-prone areas in northwestern Ethiopia, which is affected by flood hazards. Flood susceptibility modeling in this area is essential for hazard reduction purposes. For this, the analytical hierarchy process (AHP), bivariate, and multivariate statistical methods were used. Using an intensive field survey, historical record, and Google Earth Imagery, 1404 flood locations were determined which are classified into $70 \%$ training datasets and 30\% testing flood datasets using subset in the GIS tool. The statistical relationship between the probability of flood occurrence and eleven flood-driving factors is performed using the GIS tool. Then, the flood susceptibility map of the area is developed by summing all weighted factors using a raster calculator and classified into very low, low, moderate, high, and very high susceptibility classes using the natural breaks method. The results for the area under the curve (AUC) are $99.1 \%$ for the frequency ratio model is better than $86.9 \%$ using AHP, $81.4 \%$ using the logistic regression model, and $78.2 \%$ using the information value model. Based on the AUC values, the frequency ratio (FR) model is relatively better followed by the AHP model for regional flood use planning, flood hazard mitigation, and prevention purposes.
\end{abstract}

Keywords: flood, susceptibility, Geographic Information System (GIS), analytical hierarchy process (AHP), frequency ratio, information value, logistic regression, Ethiopia

\section{Introduction}

A flood is an overflow of water that submerges usually dry land. It can also occur in rivers or lakes when the flow rate exceeds the capacity of the rivers channel, particularly at the bends or meanders in the waterway and backflow from the Lakes. Natural hazards, in particular flood, has been affecting the world during rainy seasons. Even though Flood is one of the natural parts of the hydrological cycle, it is increased in both frequency and magnitude from year to year (Samanta et al. 2018). This is because of the over change of climate and land degradation on the Earth due to the anthropogenic intervention. The anthropogenic intervention on the Earth can reduce the water retention capacity of the catchments because of the cleanup of forestation for a different purpose, which resulted in a high rate of soil erosions. The Flood hazard has been causing damage to crops, infrastructures, engineering structures, properties, and loss of human and animal lives worldwide including Ethiopia. As reported by (Samanta et al. 2018; Calil et al. 2015), the flood has resulted in a risk to a human being (like loss of life, injury), properties (agricultural area, yield production, villages, and buildings), communication systems (urban 
infrastructure, bridges, roads, and railway routes), cultural heritage and ecosystems. (Zou et al. 2013; Calil et al. 2015) stated that more than 2000 deaths can occur within a single year and more than 75 million people have been adversely affected across the planet Earth by flood hazards.

Flood hazard is becoming one of the destructive natural hazards in Ethiopia followed by landslide incidences and resulted in huge damages to properties, crops, farmlands, infrastructures, and loss of life. For example, in the last two years, 20192020, flood hazard was displaced more than 500,000 people and damaged wide cultivated lands (more than 25, 000 ha cultivated lands), damaged various engineering structures, destructed more than 35 houses, and lost of lives in Amhara, Somali, Afar, SNNP, Dire Dwa, and Oromia regions of Ethiopia. The study area is one of the severely affected areas by flooding which resulted in the loss of life, properties, destruction of houses, roads, and more than 7, 000-hectare farmlands covered by various crops in the area. These show that huge economic loss caused by flooding hazard that retards the sustainable development of the economy of the country. Therefore, flood susceptibility mapping is one of the most important elements for early warning systems or strategies to prevent and mitigate future flood situation, which helps to reduce the negative results of flood hazard. Flood susceptibility mapping can be also perceived as one of the ways of vulnerability assessment (Adger et al. 2006; Jacinto et al. 2015). In geohazard mapping, susceptibility/vulnerability, hazard, and risk mapping are the most important activities to understand, mapping, and evaluating the spatiotemporal condition and level of risk due to geo-hazards. These terms have different meanings but some researchers use the terms interchangeably. Susceptibility refers to the probability of occurrence of an event within a particular type in a given location whereas hazard refers to the probability of occurrence of an event within a particular type and magnitude in a given location within a reference period. This means, susceptibility can be used to predict the spatial occurrence of events, but hazard can be used to predict the spatiotemporal occurrence of events in a given terrain. The term risk refers to the expected losses or damage by events in a given region, which are the products of susceptibility, hazard, and elements at risk. Hence, the main objective of this study is to prepare a flood susceptibility map, this study only focuses on flood susceptibility other than hazard and risk. The flood susceptibility mapping has implementing using various methods by different and numerous studies. These methods including qualitative (for example, analytical hierarchy process (AHP), quantitative (machine learning, statistical), and hydrological based methods. The hydrological methods are very simple and are based on a nonlinear concept and they are less effective to model complex features like catchments (Sahoo et al. 2009). Nowadays, these traditional methods have been replaced by automated and rule-based methods that are more suitable for flood hazard mapping (Hostache et al. 2013). SWAT (Anjum et al. 2016) and WetSpass (Nurmohamed et al. 2012) methods are examples of hydrological methods that are used to produced spatial flood susceptibility models by integrated GIS and remote sensing tools. Qualitative methods are an expert-driven approach, which required field experience specialists (Rahmati et al. 2016; Dahri and Abida 2017). Rely on the experience and professional background knowledge of experts and subjectivity is the drawback of these methods. An analytical hierarchy process (AHP) is an example of a qualitative method used by many scholars to produce a flood susceptibility model based on a multicriteria analysis framework (Karimi et al., 2018). Machine learning techniques are advanced methods that used in flood susceptibility mapping, however, a considerable processing time, the requirement of having high-performance computing systems along with specific software, and strict selection criteria for input parameters make machine learning methods less usable for a wide range of users (Ghalkhani et al. 2013; Tehrany et al. 2013). Topographic wetness index (TWI) is a commonly used very simple traditional flood hazard mapping, however, this method is used considering only the slope and flow accumulation in a region. Nevertheless, flood hazard is the result of the 
combination of several factors like soil texture, depth of groundwater, land use, vegetation cover, elevation, rainfall, stream density, distance from streams, and the depth of the riverbank. To solve the above-mentioned limitation of TWI, the use of statistical and analytical hierarchy process methods is very important to evaluate the spatial statistical correlation of flood driving factors, and flood points. Statistical methods are indirect susceptibility mapping methods widely or routinely used to evaluate the correlation between flood driving factors and floods based on mathematical expression (Bednarik et al. 2012; Chen and Wang 2007; Pradhan et al. 2011; Regmi et al. 2014; Wang et al. 2011). Statistical methods are imperative to utilize quick, understandable, and accurate methods for flood susceptibility modeling. It has no specific requirements regarding input data, software, and computer capacity. The statistical methods can be further divided into multivariate and bivariate statistical methods, which are widely used throughout the world. They provide reliable results (Dai and Lepcha 2002; Donati and Turrini 2002; Luelseged and Yamagishi 2005; Duman et al. 2006; Sarkar et al. 2013; Meten et al. 2015; Chandak et al. 2016; Kouhpeima et al. 2017; Wubalem and Meten 2020; Hong et al. 2020). The bivariate statistical methods are used to evaluate the relationship between flood governing factors and past flooding. Frequency ratio, certainty factor, information value, and weight of evidence are examples of bivariate statistical methods, which are simple, easy, and produce reliable models. It also helps to evaluate the effects of a flood at a factor class level that is impossible in data mining or multivariate methods. However, it requires quality input data, past flood data, and lacking to evaluate the relationship among flood governing factors. Multivariate statistical methods are used to examine the relationship between three and above dependent and independent variables (Pham et al. 2016b; Das 2019; Duman et al. 2006; Kouhpeima et al 2017; Luelseged and Yamagishi 2005). Logistic regression and discriminant analysis are examples of multivariate statistical methods used frequently in flood susceptibility modeling and provide reliable results (Chen and Wang 2007; Das 2019; Duman et al. 2006; Kouhpeima et al. 2017; Luelseged and Yamagishi 2005; Meten et al. 2015). However, it is incapable to examine the contribution of each factor class for flood probability like data mining, unlike bivariate methods.

Many scholars have been employing both qualitative and quantitative methods for flood susceptibility modeling, however, no clear and tangible agreements to select the best methods for flood susceptibility modeling practice. Although the suitability of the model depends on various constraints including physical parameters, data quality, and availability, expert and technological advancement, comparison among different natural hazard mapping methods is one of the solutions to select appropriate approaches. Hence, each method has its limitation, using different approaches together for landslide or flood susceptibility mapping is very important to fill the gap among the methods. For example, the logistic regression model can perform multivariate statistical analysis between a dependent variable and a set of independent variables, but it is incapable to analyze the impacts of internal classes of flood governing factors individually on flood occurrence. This limitation can be solved using bivariate statistical methods, for example, frequency ratio and information value statistical methods can be extracted the influence of each flood governing factor class on flood occurrence, but it cannot consider the relationship between these flood governing factors and flood occurrence. Therefore, the combination use of bivariate and multivariate statistical methods are very essential to overcome the limitation of each method. As a result, in the present study, bivariate, multivariate, and expert methods are employed to generate a flood susceptibility model in the sub-basin of Lake Tana and the performance of each method has been evaluated using receiver operating characteristics curve and area under the curve (AUC). Thus, based on the concerns stated overhead, the main objective of this study is 1) to compare and evaluate the performance of the frequency ratio, information value, logistic regression, and analytical hierarchy process methods to determine flood-prone areas 2) to evaluate the relationship between flood factors and flood probability as well 
as flood factor class and flood occurrence probability. The nobility of this study lies in, 1) for the first time, the rigorous flood susceptibility methods like statistical methods was conducted in the sub-basin of Lake Tana to generate flood susceptibility model 2) the comparison among the information value, frequency ratio, logistic regression, and analytical hierarchy process methods have not performed yet. This study will be determined with statistically significant methods for flood susceptibility modeling. The resulted map will be helped the regional and local authorities and policymakers to mitigate flood hazards.

\section{Study Area}

The study area is located in Amhara Regional State of the sub-basin of Lake Tana basin in northwestern Ethiopia, which is characterized, by wide flat to gently sloping plains and somehow raged topography. Its elevation ranges from 1,774-4,037 $\mathrm{m}$ above mean sea level (Fig. 1). It is bound between 330,000-410, $000 \mathrm{E}$ and 1,280,000-1,350,000 N. It is characterized by subtropical to cool climatic zones with very high and prolonged rainfall between Jun to October. The study area is covered mainly three Districts including Fogera, Farta, and Libo Kemkem which is frequently affected by flood hazards yearly during heavy and prolonged rainfall seasons. The study area has many tributaries that drained to the two major rivers called Gumara and Ribb Rivers that also drained to Lake Tana, which is the parts of the Abay basin. Agriculture is one of the most dominant land use in the study area, which is performed more than two per year. The dominant soil types in the study area including clay, loam, sandy loam, silty sand, fine to coarse sand, and gravels sourced from volcanic rocks.

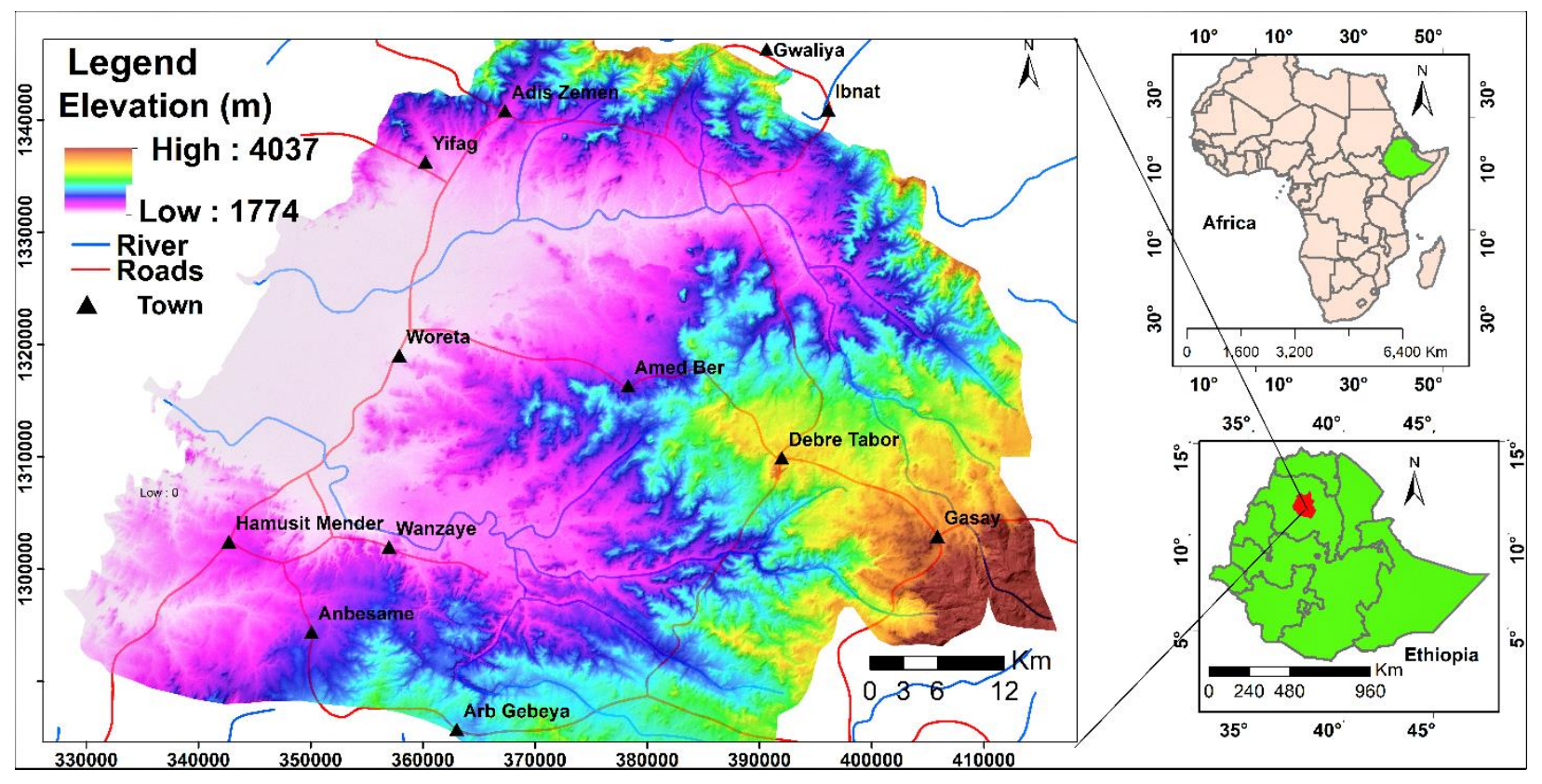

Figure 1 Location Map of the Study Area

\section{Data Used}




\section{Flood Inventory Map}

In flood susceptibility mapping, flood inventory mapping is one of the key elements, which can be prepared using various techniques like the aerial photograph or Google Earth Imagery interpretation, field investigation, and evaluation of archived data coupled with GIS tool. Evaluating and recognizing the correlation between flood driving factors and flood incidences is required an accurate and precise flood inventory map (Pradhan et al. 2012; Tehrany and Jones 2017; Mahyat et al. 2019). This flood inventory map can be prepared in map forms from the data that can be collected from a satellite image or Google Earth Imagery interpretation, historical records, and extensive field survey. In the present research work, 1404 most relevant flood inventory data were collected from historical records, Google Earth Imagery interpretation, and Extensive fieldwork (Fig. 2). In the literature, several suggestions are provided regarding the size of flood samples to be used for modeling and model verification (Ohlmacher and Davis 2003). Therefore, based on a literature review, the flood inventory data was classified into 70\% (983) flood for the training dataset and 30\% (421) for testing datasets keeping their spatial distribution using subset in ArcGIS 10.1 (Lee et al. 2012; Tehrany et al. 2013; Khosravi et al. 2016; Mahyat et al. 2019) as shown in the figure. The same number of flood and non-flood points were chosen for the logistic regression analysis. 


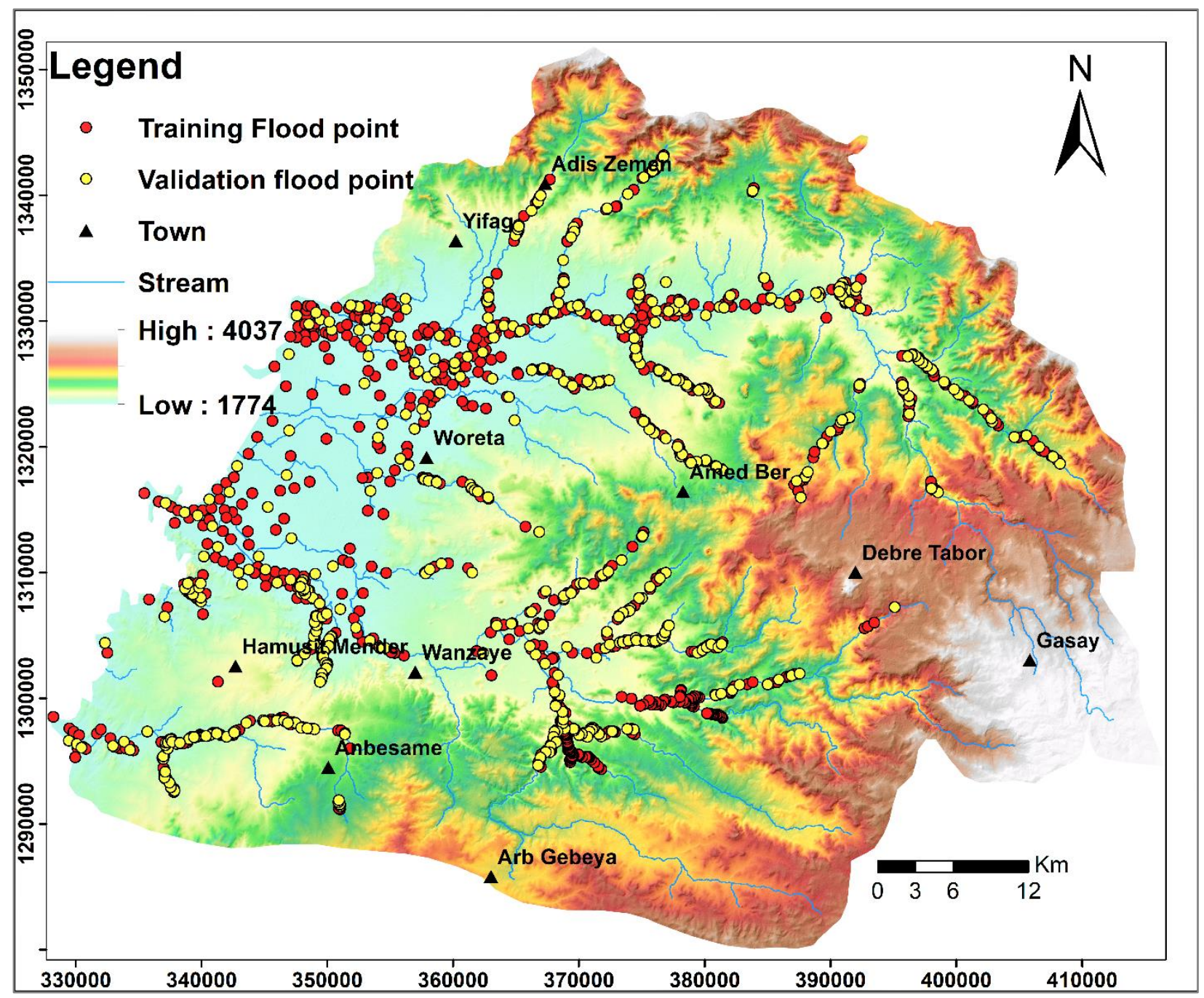

Figure 2 Flood location map

\section{Flood Driving Factors}

The selection of flood factors is one of the most crucial elements in flood susceptibility mapping, which depend on physical and natural characteristics of the study area and data availability (Kia et al. 2012; Liuzzo et al. 2019), however, no welldefined standards to select the most significant flood driving factors. The factors that initiate the flood incidence in the study area are selected based on the study area's environmental condition, data availability, logistic regression analysis, and a literature review (Lee et al 2012; Mahyat et al. 2019). The slope angle, slope curvature, land use, soil texture, distance to stream/river, stream density, normalized vegetation index, flow accumulation, groundwater depth, rainfall, and elevation have been taken into account to examine the spatial relationship between them and flood occurrence in the study area. These factors were classified into sub-factor classes using a natural break in ArcGIS to evaluate the effects of each flood factor class for the case of frequency ratio and information vale methods. The flood factors, which have derived from DEM, distance to stream (five classes), slope angle (five classes), flow accumulation (five classes), stream density (five classes), elevation (five classes), and slope curvature (three classes) maps were constructed from $12.5 \mathrm{~m}$ x $12.5 \mathrm{~m}$ resolution DEM (Fig. 3). The soil map of the study area is prepared through digitization from a 1:250,000 textural soil map of the Amhara 
Region, which has four classes (silty sand, sandy loam, clay, and loam). Land use and NDVI maps of the study area were prepared from Sentinel 2 satellite image analysis using ArcGIS with the help of high-resolution Google Earth image interpretation. The LULC has eight classes including grazing land, agricultural land, barren land, residential/settlement, river zone /water body, dense forest, moderate forest, and wetland (Fig. 3) whereas NDVI has five classes. The rainfall and groundwater depth raster map was constructed using ArcGIS 10.1 from annual mean rainfall and well data that are collected from Amhara Metrological Agency and Amhara Water Well Drilling Enterprise, respectively. To determine the effects of each flood factor class on flood occurrence, weight rating through flood factor raster combined with flood raster map is important. For this purpose, all flood factor maps converted into a raster and reclassified with the same pixel size (12.5 $\mathrm{m} \mathrm{x}$ $12.5 \mathrm{~m}$ ) and the same projection using the GIS tool. Then, the flood inventory map is overlaid through a combination of spatial analysis tools under the local toolbox with flood factor raster class to extracted flood pixels for each flood driving factor class. Then the effects of each factor class were determined using the equation of frequency ratio, and information value methods as summarized in Table 1. 

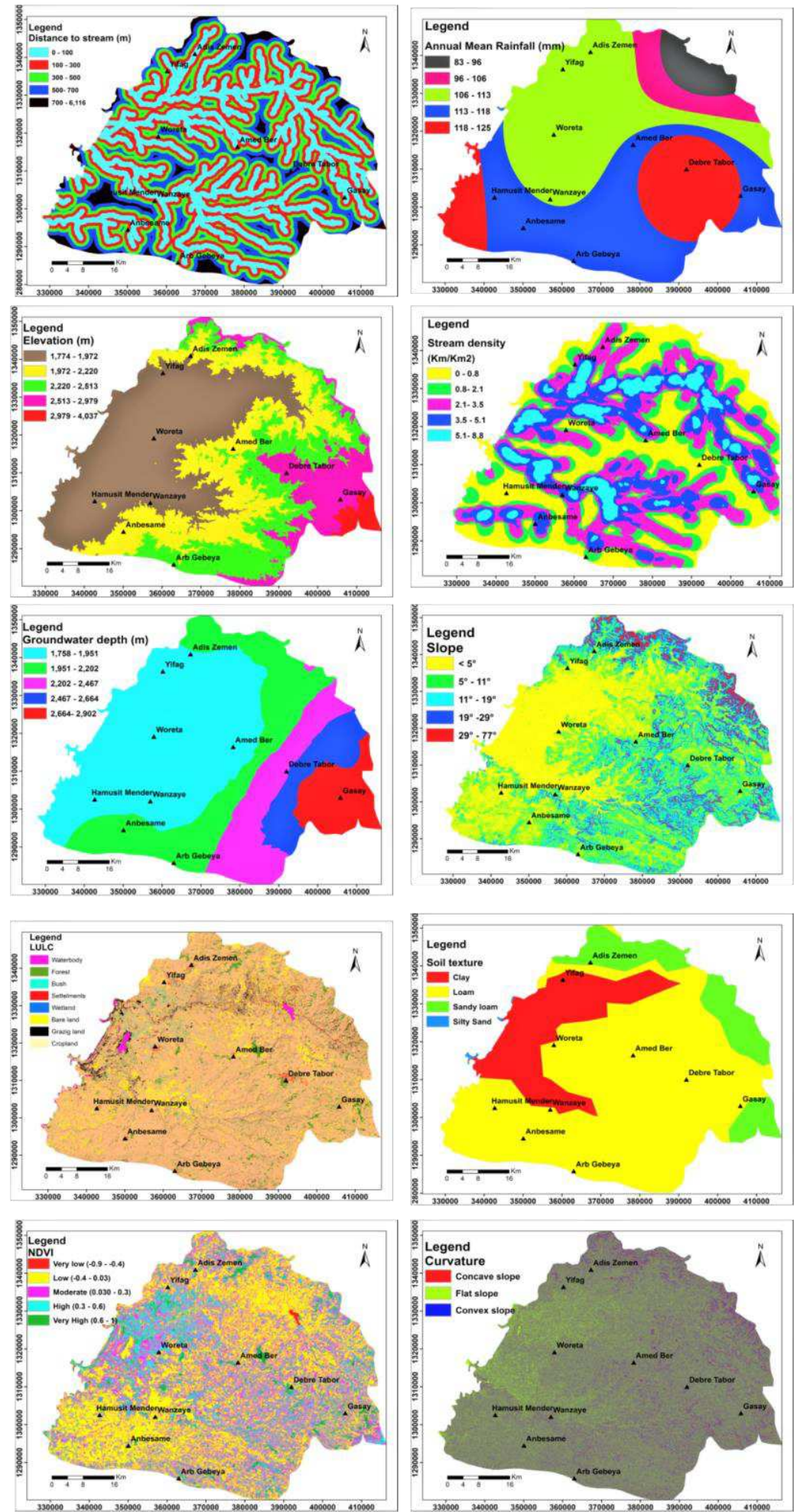

Figure 3 Flood governing factor maps 


\section{Methodology}

To achieve the goal of the present research work, various activities and steps are employed. These are data collection, Flood inventory mapping, database creation for Flood factors, Flood susceptibility modeling using frequency ratio, information value, logistic regression, and AHP methods as well as model validation using the Receiver Operating Characteristics curve (ROC). Moreover, appropriate data, including a topographic map, borehole data, Digital Elevation Model (DEM) with 12.5 $\mathrm{m}$ resolution, historical flood events, soil type map, geological map, and meteorological data were collected. These data were collected from the United States Geological Survey (USGS), Amhara Water Well Drilling Enterprise (AWWDE), Field Survey, Google Earth Imagery from NASA, Ethiopian National Meteorological Agency, and the Geological Survey of Ethiopia (GSE). The flood location of the study area was identified using historical records, Google Earth imagery analysis, and an intensive field survey. This was classified into training and testing flood datasets. The training flood datasets were used for model preparation, whereas the testing flood datasets were used for model prediction accuracy evaluation. Based on the data availability, local environmental conditions, data evaluation, literature, and local people interview, eleven flooddriving factors were determined. The flood driving factor maps and flood inventory map were prepared using ArcGIS 10.1. Geodatabase building is one of the most fundamental elements in flood susceptibility mapping. Therefore, four databases were built for information value, logistic regression, frequency ratio, and analytical hierarchy process (AHP) models. The frequency ratio, information value, and analytical hierarchy process (AHP) database contain flood inventory and flood driving factors while the logistic regression database contains flood and no flood points with eleven- weighted flood driving factors. After the database was built, an evaluation of the relationship between flood and flood factors as well as the determination of the statistical significance of each flood factor was the next step in flood susceptibility mapping. Therefore, eleven flood factor maps were reclassified into subclass and overlaid with reclassified training flood datasets. Weight ratings for all flood factor classes assigned statistically using Excel. These weighted maps rasterized-using lookup in spatial analyst. After rasterized the factor maps, the flood susceptibility index maps were generated by the sum-up of all raster maps using a raster calculator in Map Algebra. These maps (LSI) are classified into a fivefold classification scheme: very low, low, moderate, high, and very high susceptibility classes using natural breaks (Fig. 5, 6, 7, and 8). In the case of the logistic regression method, the study area is classified as training flood and non-flood points using GIS. Then, the weight of eleven factors has been extracted to generate logistic regression coefficients of each flood factor in SPSS, and finally, the flood susceptibility index of the area was generated using the logistic flood probability equation (Eq. 8) and GIS tools (Fig. 3). Finally, the accuracy of the four models evaluated using the prediction rate curve based on observed testing flood datasets (Fig. 9).

\section{Modeling Approaches}

\section{Information Value Model}

The information value method is one of the probabilistic methods of a bivariate statistical method, which is used to envisage the correlation between floods and flood factor classes (Sakar et al. 2006). The information values for each factor class determined through the combination of reclassified flood raster to reclassified flood factor raster based on the presence of flood in a given map unit. These values are important to define the role of each causal factor in classes for flood occurrence. This can calculate as in Eq.1. 


$$
\mathrm{IV}=\ln \left(\frac{\text { Conditional probability (CP) }}{\text { Prior probability (PP) }}=\frac{\frac{\text { Nfopix }}{\text { Ncpix }}}{\frac{\text { Ntfopix }}{\text { Ntcpix }}}\right.
$$

Where Conditional probability is the ratio of the pixel of a flood in class to the pixel of a class and prior probability is the ratio of the total number of pixels of the flood to the total number of pixels of the study area. Nfopix is a flood pixel/area in a flood factor class. Ntfopix is the total area of a flood in the entire study area. Ncpix is the area of the class in the study area and Ntcpix is the total pixel area in the entire study area. When the IV $>0.1$, the flood occurrence with the factor classes have a high correlation, means it will have a high probability of flood occurrence however when the IV $<0.1$ or IV $<0$, it is a low correlation between flood factors and flood occurrence which indicate a low probability of flood occurrence. After calculated the information value for each flood factor class using Microsoft excel and GIS, the information value for each factor class was assigned through the join in the ArcGIS tool. Then, the weighted flood factors rasterized using the lookup tool in spatial analysis, and the flood susceptibility index (LSI) of the study area was calculated as in Eq. 2.

$$
L S I=\sum_{i=1}^{n} I_{i} X_{i}
$$

$$
\begin{gathered}
L S I=I V * \text { Slope } \text { raster }+I V * \text { drainage density }+I V * \text { groundwater depth }+I V * \text { rainfall }+I V * N D V I+I V \\
\quad * \text { flow accumlation }+I V * \text { aspect raster }+I V * \text { curvature raster }+I V * \text { soil raster }+I V \\
\quad * \text { Land use raster }+I V * \text { Distance to stream raster }
\end{gathered}
$$

Where LSI is the flood susceptibility index and IV is the information value of each factor class. The higher value of LSI has indicated a higher probability of flood occurrence.

\section{Logistic Regression Model}

Logistic regression is one of the popular multivariate statistical analysis methods, which can be used to establish a multivariate regression relationship between the dependent and independent variables (Pradhan and Lee 2010). Among other statistical methods, the logistic regression model has been proven one of the most reliable approaches for flood susceptibility mapping to determine the most flood influencing factors (Luelseged and Yamagishi 2005; Chau and Chan 2005; Lee and Sanbath 2006; Chen and Wang 2007; Ricki and Graf 2009]. This model is advantageous, as it does not require normal distribution and it uses continuous or discrete variables. The difficulty of using the logistic regression model lies in the sample size selection of dependent and independent variables for flood susceptibility analysis. There are three ways of sampling flood and non-flood points (Zhag et al. 2017). The first way is using all data from all the study areas. However, this leads to an uneven proportion of non-flood and flood pixels, which incorporate a large volume of data in the analysis. Using all flood pixels with equal non-flood pixels is the second method, which also results in a less reliable output, but it can reduce sample size and sampling bias. The third method uses an unequal or equal proportion of flood and non-flood pixels by classifying flood into training and testing datasets.

In the present work, the floods of the study area were classified into training flood datasets (70\%) and as testing flood datasets $(30 \%)$. In this study, the dependent data are a binary variable and are made up of 0 and 1 , which represent the absence and presence of floods, respectively. Consequently, an equal number of non-flood sample points, whose dependent 
variable value is 0 were randomly selected from flood-free areas to represent the absence of floods using GIS. The equal number of flood points and non-flood points were merged. Moreover, all the values of independent variables containing flood and non-flood were extracted from the maps of each flood governing factors using ArcGIS. Then, the logistic regression was conducted and coefficients were calculated in the SPSS program. It can be expressed mathematically (Lee and Sambath 2006; Schicker and Moon 2012) as:

$$
P=\frac{1}{1+e^{-z}} \quad------\quad-(3)
$$

Where $\mathrm{P}$ is the probability of flood occurrence that varies from zero to one. $\mathrm{Z}$ is the linear combination of the predictors and varies from $-1<\mathrm{z}<0$ for higher odds of non-flood occurrence to $0<\mathrm{z}<1$ for odds of higher flood occurrence. $\mathrm{Z}$ can be defined as:

$$
Z=\beta_{0}+\beta_{1} X_{1}+\beta_{2} X_{2}+\beta_{3} X_{3} \ldots \beta_{n} X_{n} B n X n-----------(4)
$$

Where $x_{1}, x_{2}, x_{3} \ldots x_{n}$ are independent variables, Bo is the intercept of the slope of logistic regression analysis, and $\beta_{1}, \beta_{2}, \beta_{3} \ldots$ $\beta_{\mathrm{n}}$ are the coefficients of the logistic regression analysis.

\section{Frequency Ratio Model}

It is one of the bivariate probability methods, which is applicable to determine the correlation between flood occurrence and flood causative factor classes. The frequency ratio is the ratio of areas where the flood occurred in the areas to areas in which flood has not occurred. When the ratio value is greater than one, it indicates a strong correlation between factor classes and flood occurrence in a given terrain, however, the ratio value less than one indicated a weak correlation between flood occurrence and flood factors, which means a low probability of flood occurrence (Lee and Talib, 2005). It can calculate using Eq. 5.

$$
\mathrm{F} R=\frac{a}{b}=\frac{\frac{\text { Nfopix }}{\text { Ntfopix }}}{\frac{\text { Ncpix }}{\text { Ntcpix }}}
$$

Where FR is frequency ratio, Nfopix is a flood pixel/area in a flood factor class, Ntfopix is the total area of a flood in the entire study area (a), Ncpix is an area of the class in the study area and Ntcpix is the total pixel area in the entire study area (b). In the present research work, the frequency ratio for each causative factor class calculated using Eq.5, and the results are summarized in Table 1.

After calculated the frequency ratio for each flood factor class using Microsoft Excel and GIS, the frequency ratio value for each factor class was assigned through the join in the ArcGIS tool. Then the weighted flood factors rasterized using the lookup tool in spatial analysis. The flood susceptibility index (LSI) of the study area was calculated by carefully summing up the weighted factor raster maps using Eq. 6 by the raster calculator in Map Algebra of the spatial analysis tool. To get the flood susceptibility index, the frequency ratio of each factor type or class is summed as in Eq. 6. The flood susceptibility index indicated the degree of susceptibility of the area for flood occurrence.

$$
\mathrm{LSI}=\sum_{\mathrm{i}=1}^{\mathrm{n}} \mathrm{FR}_{\mathrm{i}} \mathrm{X}_{\mathrm{i}}
$$




$$
\begin{gathered}
L S I=F R * \text { Slope } \text { raster }+F R * \text { drainage density }+F R * \text { groundwater depth }+F R * \text { rainfall }+F R * N D V I \\
+F R * \text { flow accumlation }+F R * \text { aspect raster }+F R * \text { curvature raster }+F R * \text { soil raster } \\
+F R * \text { Land use raster }+F R * \text { Distance to stream raster }
\end{gathered}
$$

Where LSI is the flood susceptibility index, $n$ is the number of flood factors, $X_{i}$ is the flood factor and FR is the frequency ratio of each flood factor type or class. After the flood susceptibility index was calculated, the index values were classified into different levels of flood susceptibility zones using natural breaks in the ArcGIS tool. The higher the value of the flood susceptibility index (LSI), the higher the probability of flood occurrence, but the lower the LSI indicates, the lower the probability of flood occurrence.

Based on the natural break classification, the flood susceptibility map of the study area has five classes such as very low, low, moderate, high, and very high landslide susceptibility class (Fig. 5).

\section{Analytical Hierarchy Process (AHP)}

The AHP is one of the qualitative methods used to determine the relationship between flood factor class and flood occurrence. The AHP method is a structured tool that is used to analyze difficult decisions based on mathematics and psychology (Cho et al. 2015; Nguyen et al. 2015; Saaty 2000; Zhang et al. 2016). To produce weighting factors, the pairwise comparison method was used by considered Saaty's ranking scale (Luu et al. 2018; Saaty 2008). The consistency of calculated weight for each flood factor class was examined by the consistency ratio, which is calculated by Eq.7 (Luu et al. 2018; Saaty 2001). When the consistency ratio (CR) is less than 0.1, the weight of the factor class that is calculated using the comparison matrix is consistent but if it is greater than 0.1 , the comparison matrix is inconsistent and should be revised. After the weight of each factor class was determined, the flood susceptibility map was produced as showed in Eq.9 (Rahmati et al., 2016c).

$$
\begin{aligned}
& \mathrm{CR}=\frac{C I}{R I} \quad \text { (7) } \quad \mathrm{CI}=\frac{\lambda_{\max }-n}{n} \\
& F S I=\sum_{i=1}^{n} W_{i} * X_{n} \\
& L S I=W * \text { Slope raster }+W * \text { drainage density }+W * \text { groundwater depth }+W * \text { rainfall }+W * N D V I+W \\
& * \text { flow accumlation }+W * \text { aspect raster }+W * \text { curvature raster }+W * \text { soil raster }+W \\
& * \text { Land use raster }+W * \text { distance to stream raster }
\end{aligned}
$$

Where $\mathrm{CR}$ is consistency ratio, $\mathrm{CI}$ is consistency index, $\mathrm{RI}$ is the average random consistency index of the judgment matrix and $\lambda_{\max }$ is the largest eigenvalue derived from the paired comparison matrix and $\mathrm{n}$ is the number of flood factor, Wi is the weight of the flood factor, $\mathrm{X}_{\mathrm{n}}$ is the flood factors and FSI is flooded susceptibility index.

\section{Result and Discussion}

\section{Correlation of Flood Factors and Flood Incidence}

\section{Frequency Ratio Results}

The frequency ratio method is used to calculate FR for each subclass of every flood-driving factor, which is the ratio of flood occurrence ratio to the area ratio. The result of the FR is summarized in Table 1. The greater the value of FR indicates a strong correlation between flood factor class and flood occurrence, the higher probability of flood occurrence when FR greater than unity (Table 1 and Fig. 4). As the results of the analysis designated in Table 1 and Fig. 4), the FR value for the 
first slope class, $0^{\circ}-5^{\circ}$ is greater than 1 , is indicating a higher probability of flood occurrence which has $96 \%$ of a flooded area in the slope classes. This finding is consistent with other studies (e.g., Rahmati and Pourghasemi 2017; Tehrany et al. 2014; Shafizadeh et al. 2018). However, the slope gradient greater than $5^{\circ}$ has less correlation with flood occurrence. This result confirmed that the concepts as the slope gradient increase, the probability of flood occurrence in a given train will be decreased. Because the steeper the slope gradient, the higher will be the rate of downslope water velocity however the lower the water concentration as well as the infiltration of rainwater into the ground. Nevertheless, when the slope gradient decreases, the potential for surface water concentration and rainwater infiltration into the ground will increase it depends on the hydraulic behavior of soil in that region. The higher concentration of surface water will have resulted in a high probability of flood incidence.

Slope curvature is another flood factor, which has three classes including Convex, Concave, and flat slope shapes. As the results of the correlation analysis of curvature class with flood inventory indicated in Table 1, the flat class received a higher FR value, indicating a strong correlation with flood occurrence. $56.1 \%$ of the flooded area is fall in this class. This is because of the higher potential of rainwater concentration and low infiltration of rainwater due to its flatness and the existence of impermeable soil formation. Hence, this class is flat; the overflow of the water from the riverbed is high in a class that is why the flat portion of the curvature class indicating a higher flood occurrence probability. This finding is confirmed with the other studies (Cao et al. 2016; Chapi et al. 2017; Khosravi et al. 2016; Shafizadeh et al. 2018).

Table 1 indicated that the FR value for elevation class is decreased as the elevation of the region is increased (Shafizadeh et al. 2018), indicating a higher flood probability correlation with the first class of $1,774-1,972 \mathrm{~m}$ which is $99 \%$ of the flooded area fall in this region. As indicated in Table 1, the relationship between elevation and the relative likelihood of flood occurrence is a negative correlation at the elevation $>1,972 \mathrm{~m}$, meaning the probability of flood occurrence is low in elevated lands than low lands (Shafizadeh et al. 2018). This result is similar to the previous studies of (Hong et al. 2016; Shafizadeh et al. 2018).

In the spatial prediction of flood-prone areas in a catchment, distance to the river is a critical factor because floods occur due to the overflowing of water from the riverbanks (Chapi et al. 2017). Therefore, the areas closer to the riverbeds demonstrate a rapid response to rainstorms and flooding. As the results of the analysis shown in Table 1, the first four classes $(0-100 \mathrm{~m}, 100-300 \mathrm{~m}, 300-500 \mathrm{~m}$, and $500-700 \mathrm{~m})$ indicating a strong correlation with flood occurrence and $57.1 \%$ of flooded area falls in these classes but the value of FR is decreased as the distance to the river bed is increased. This result confirmed that the concepts, the closer to the riverbed, the higher would be flood occurrence probability (Chapi et al. 2017; Hong et al. 2020; Shafizadeh et al. 2018). As the correlation analysis of flow accumulation with flood inventory results indicated in Table 1, flow accumulation is one of the most important parameters in flood susceptibility mapping (Pradhan 2010). The higher value of FR for flow accumulation is indicating higher concentration of water and consequently higher flood occurrence probability. As Table 1 indicated, when the flow accumulation increased, the FR value is increased in parallel. Land use and land cover are other important parameters in flood susceptibility mapping which can be influenced by the interrelationship between surface and groundwater, the amount of infiltration, surface water concentration, and overland flow. As the result of land use and flood inventory correlation analysis indicated in Table 1, River zone, barren land, grazing land, settlement, and moderate vegetation/cropland have higher FR value, indicating higher flood occurrence probability. $37 \%$ of flooded area falls in these land-use classes. Because the moderate vegetation/cropland favors rainwater 
infiltration and hence the groundwater of this region is shallow, which enhanced the overland flow of water that is why moderate vegetation class has received higher FR value. The urban and grazing land have received higher FR value because of the impermeable nature of the class and indicating a higher flood occurrence probability correlation. This result is in line with the work of (Shafizadeh et al. 2018). The NDVI is one of the important parameters for flood susceptibility mapping, its value ranges from -1 to 1 . When the value is closer to one, the higher vegetation cover but the closer to -1 implies the lower vegetation cover. Higher NDVI indicated dense vegetation that can reduce and slow water flow (Turoglu and Dolek 2011). This gives the water time to infiltrate into the ground and resulting in a decrease in water volume and less probability of flood occurrence. However, it depends on the hydraulic behavior of soil and the depth of groundwater. In this study, the NDVI value ranges from -1 to 1 which is from non-vegetated to highly vegetated regions. As the vegetation density increased, the flood susceptibility of a region will be decreased depending on the depth of groundwater and vegetation type. As the results of NDVI with flood inventory correlation analysis indicated in Table 1, the first, third, fourth, and fifth classes of the NDVI have received a higher value of FR and indicating higher flood occurrence probability correlation. This is because the groundwater depth of the study area is shallow which can be increased overland flow water by reducing the rate of infiltration of rainwater that is why the region shows a higher flood occurrence correlation. $60.4 \%$ of the flooded area falls in these classes. Table 1 shows, as a stream density increased, the value of FR is increased in parallel and indicating high flood occurrence probability (Chapi et al. 2017; Shafizadeh et al. 2018). The stream density classes $\left(3.5-5.1 \mathrm{~m} / \mathrm{km}^{2}\right.$ and $5.1-8.8 \mathrm{~m} / \mathrm{km}^{2}$ ) have received a high value of FR, indicating a strong correlation with flood occurrence and $61.5 \%$ of flooded area falls in these classes.

The amount of surface water concentration and rainwater infiltration rate mainly depends on the hydraulic behavior of soils in the region. When the soil mass in a region is highly pervious, the rate of water infiltration into the ground would be higher but the amount of surface water concentration would be lower. This will enhance the non-flood incidence probability in a region. However, this will be highly affected by the depth of groundwater. The results of flood inventory with soil correlation analysis indicated in Table 1, silty sand and clay soil mass have received higher value of FR compared to loam and sandy loam soil masses, indicating higher flood incidence probability. This is because of the impervious behavior of fine-grained soils. When the grain size of soil mass increased, the percent of pore space in between soil grain will increase but the pore space diameter will low. This leads to the blockage of flowing water inside the soil. These types of soil will have a high water holding capacity. This again increased the overland flow of water. This can be contributed to high flood incidence probability. $88 \%$ of the flooded area falls in the silty sand and clay soil masses. Table 1 indicated the shallow groundwater class has received a high value of FR, indicating high flood incidence probability. $97.2 \%$ of the flooded area falls in very shallow groundwater depth. Even though rainfall is one of the most important flood driving factors, its effect highly depends on the nature of the ground and the depth of the river channel. As a result of rainfall with flood inventory analysis indicated in Table 1, the annual mean rainfall of class (106-113 mm) has received a high value of FR, indicating high flood incidence probability. This is because of the impervious hydraulic behavior of soil mass, low slope gradient, and shallow groundwater depth. $68.5 \%$ of the flooded area falls in the class $(106-113 \mathrm{~mm})$. 

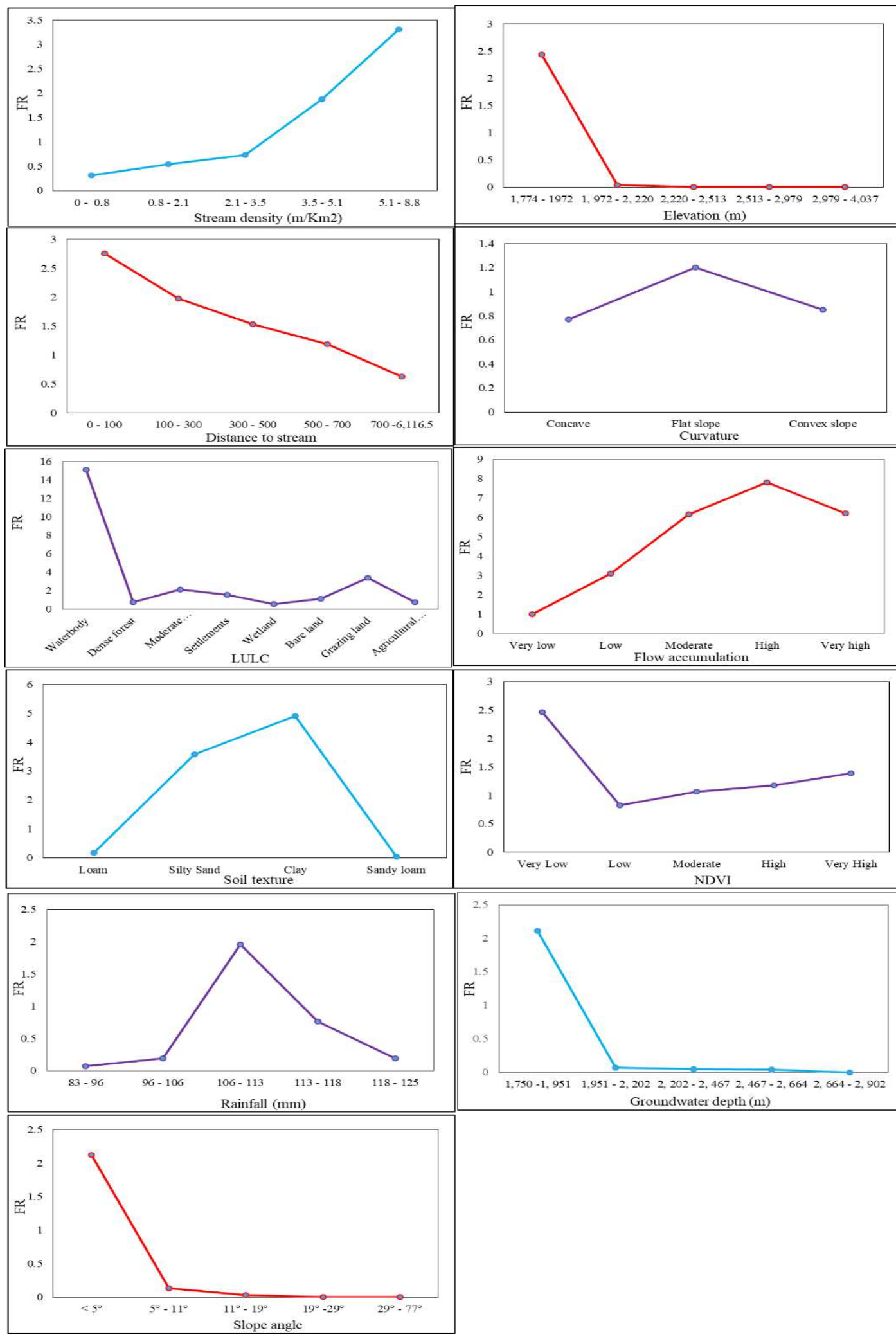

Figure 4 Statistical relationship between flood occurrence and flood driving factors 


\section{Information value Results}

ArcGIS 10.2 and Microsoft Excel were used to calculate the information value (IV) of each factor classes to determine the statistical significance of each factor class for flood incidence probability. The factor class, which received higher (positive) information value indicating higher flood occurrence probability, but the factor class, which has received lower (negative) information value indicating a negative or weak correlation with flood occurrence probability. For example, as the result shown in Table 1, the distance to the stream of the first four classes indicating a positive correlation with flood occurrence but the rest factor class of the distance to stream, show negative correlations for flood occurrence probability. The slope class $>5^{\circ}$, elevation $>1,972 \mathrm{~m}$, the first class of flow accumulation, distance to stream class $>700 \mathrm{~m}$, the stream density classes $\left(0-0.8 \mathrm{Km}^{2}, 0.8-2.1 \mathrm{Km}^{2}\right.$, and $2.1-3.5 \mathrm{Km}^{2}$ ), slope curvature (concave \& convex slope), LULC (dense forest, wetland, and agriculture land), the second and the third classes of NDVI, Soil texture (sandy loam \& loam), and groundwater depth > 1, $951 \mathrm{~m}$ did show negative statistical correlation with flood occurrence probability (Table 1).

Table 1 Statistical analysis results of flood occurrence and flood factors using FR, and IV methods

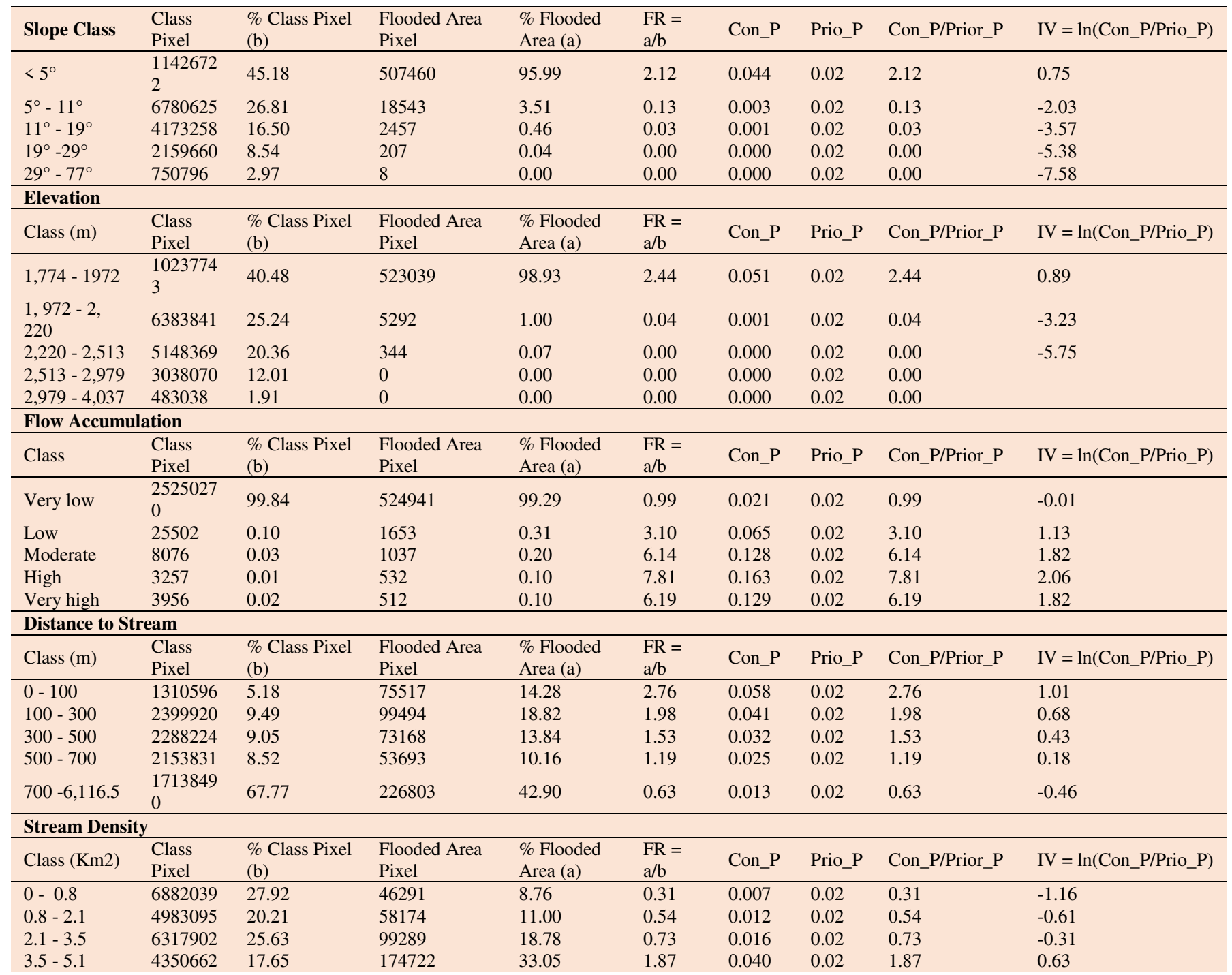




\begin{tabular}{|c|c|c|c|c|c|c|c|c|c|}
\hline $5.1-8.8$ & 2118013 & 8.59 & 150199 & 28.41 & 3.31 & 0.071 & 0.02 & 3.31 & 1.20 \\
\hline Concave & 4388463 & 17.35 & 71032 & 13.44 & 0.77 & 0.016 & 0.02 & 0.77 & -0.26 \\
\hline Flat slope & $\begin{array}{l}1184002 \\
2\end{array}$ & 46.82 & 296510 & 56.09 & 1.20 & 0.025 & 0.02 & 1.20 & 0.18 \\
\hline $\begin{array}{l}\text { Convex } \\
\text { slope }\end{array}$ & 9062576 & 35.83 & 161133 & 30.48 & 0.85 & 0.018 & 0.02 & 0.85 & -0.16 \\
\hline Waterbody & 170378 & 0.67 & 53875 & 10.19 & 15.13 & 0.316 & 0.02 & 15.13 & 2.72 \\
\hline Dense forest & 1584350 & 6.27 & 25202 & 4.77 & 0.76 & 0.016 & 0.02 & 0.76 & -0.27 \\
\hline $\begin{array}{l}\text { Moderate } \\
\text { forest }\end{array}$ & 185078 & 0.73 & 8200 & 1.55 & 2.12 & 0.044 & 0.02 & 2.12 & 0.75 \\
\hline Settlements & 291928 & 1.15 & 9189 & 1.74 & 1.51 & 0.031 & 0.02 & 1.51 & 0.41 \\
\hline Wetland & 72446 & 0.29 & 812 & 0.15 & 0.54 & 0.011 & 0.02 & 0.54 & -0.62 \\
\hline \multicolumn{10}{|l|}{ NDVI } \\
\hline Class & $\begin{array}{l}\text { Class } \\
\text { Pixel } \\
\end{array}$ & $\begin{array}{l}\text { \% Class Pixel } \\
\text { (b) }\end{array}$ & $\begin{array}{l}\text { Flooded Area } \\
\text { Pixel }\end{array}$ & $\begin{array}{l}\% \text { Flooded } \\
\text { Area (a) }\end{array}$ & $\begin{array}{l}\mathrm{FR}= \\
\mathrm{a} / \mathrm{b}\end{array}$ & Con_P & Prio_P & Con_P/Prior_P & $\mathrm{IV}=\ln ($ Con_P $/$ Prio_P $)$ \\
\hline Very Low & 101398 & 0.26 & 3352 & 0.63 & 2.47 & 0.033 & 0.01 & 2.47 & 0.90 \\
\hline Low & $\begin{array}{l}1876229 \\
5\end{array}$ & 47.48 & 209315 & 39.59 & 0.83 & 0.011 & 0.01 & 0.83 & -0.18 \\
\hline Moderate & $\begin{array}{l}1157186 \\
6\end{array}$ & 29.28 & 165084 & 31.23 & 1.07 & 0.014 & 0.01 & 1.07 & 0.06 \\
\hline High & 6389220 & 16.17 & 100817 & 19.07 & 1.18 & 0.016 & 0.01 & 1.18 & 0.17 \\
\hline Very High & 2692708 & 6.81 & 50107 & 9.48 & 1.39 & 0.019 & 0.01 & 1.39 & 0.33 \\
\hline \multicolumn{10}{|l|}{ Soil Texture } \\
\hline Class & $\begin{array}{l}\text { Class } \\
\text { Pixel }\end{array}$ & $\begin{array}{l}\% \text { Class Pixel } \\
\text { (b) }\end{array}$ & $\begin{array}{l}\text { Flooded Area } \\
\text { Pixel }\end{array}$ & $\begin{array}{l}\% \text { Flooded } \\
\text { Area (a) }\end{array}$ & $\begin{array}{l}\mathrm{FR}= \\
\mathrm{a} / \mathrm{b}\end{array}$ & Con_P & Prio_P & Con_P/Prior_P & $\mathrm{IV}=\ln ($ Con_P/Prio_P $)$ \\
\hline $\begin{array}{l}1,951-2, \\
202\end{array}$ & 6130330 & 24.24 & 9137 & 1.73 & 0.07 & 0.001 & 0.02 & 0.07 & -2.64 \\
\hline $\begin{array}{l}2,202-2, \\
467\end{array}$ & 3367218 & 13.31 & 3792 & 0.72 & 0.05 & 0.001 & 0.02 & 0.05 & -2.92 \\
\hline $\begin{array}{l}2,467-2, \\
664\end{array}$ & 2064256 & 8.16 & 1725 & 0.33 & 0.04 & 0.001 & 0.02 & 0.04 & -3.22 \\
\hline $\begin{array}{l}2,664-2, \\
902\end{array}$ & 2085293 & 8.25 & & 0.00 & 0.00 & 0.000 & 0.02 & 0.00 & \\
\hline \multicolumn{10}{|l|}{ Rainfall } \\
\hline Class & $\begin{array}{l}\text { Class } \\
\text { Pixel } \\
\end{array}$ & $\begin{array}{l}\% \text { Class Pixel } \\
\text { (b) }\end{array}$ & $\begin{array}{l}\text { Flooded Area } \\
\text { Pixel }\end{array}$ & $\begin{array}{l}\% \text { Flooded } \\
\text { Area (a) }\end{array}$ & $\begin{array}{l}\mathrm{FR}= \\
\mathrm{a} / \mathrm{b}\end{array}$ & Con_P & Prio_P & Con_P/Prior_P & $\mathrm{IV}=\ln ($ Con_P/Prio_P $)$ \\
\hline $83-96$ & 1207382 & 4.77 & 1763 & 0.33 & 0.07 & 0.001 & 0.02 & 0.07 & -2.66 \\
\hline $96-106$ & 1641787 & 6.49 & 6480 & 1.23 & 0.19 & 0.004 & 0.02 & 0.19 & -1.67 \\
\hline $106-113$ & 8856030 & 35.02 & 362318 & 68.53 & 1.96 & 0.041 & 0.02 & 1.96 & 0.67 \\
\hline $113-118$ & 8706231 & 34.42 & 139032 & 26.30 & 0.76 & 0.016 & 0.02 & 0.76 & -0.27 \\
\hline $118-125$ & 4879631 & 19.29 & 19082 & 3.61 & 0.19 & 0.004 & 0.02 & 0.19 & -1.68 \\
\hline
\end{tabular}

IV is information value, FR is frequency ratio, a is flooded area in a factor class, $\mathrm{b}$ is an area of factor class, Con_P is conditional probability and Prio_P is the prior probability 


\section{Logistic Regression Results}

Hence, sets of independent variables are so sensitive for collinearity (interrelatedness of independent variable) which can be checked using Tolerance (TOL) and variance inflation factor index (VIF), Multicollinearity test was applied using SPSS software before logistic regression analysis. When the Tolerance (TOL) $<0.2$ and VIF $>5$, the given independent variable have multicollinearity. As a result of the multicollinearity test indicated in Table 2, no independent variables that were used in flood susceptibility analysis showed any multicollinearity. Using logistic regression analysis in SPSS, the logistic regression coefficient for all flood-driving factors was determined. Similar to the information value method, the positive logistic regression coefficients indicating a positive association with flood occurrence probability but the negative logistic regression coefficients indicating a negative correlation of flood factors with flood occurrence probability. As the result of logistic regression analysis indicated in Table 2, Stream density, NDVI, Rainfall, and Curvature have received negative logistic regression coefficients but the remaining factors that have received positive logistic regression coefficients, indicating the flood factors have positively associated with flood occurrence probability.

Table 2 logistic coefficients of flood factors and multicollinearity statistics

\begin{tabular}{cc|c|c|}
\hline & & \multicolumn{2}{|c|}{ Collinearity Statistics } \\
\hline Factors & LR Coefficients $(\beta)$ & Tolerance (TOL) & Variance inflation factor index (VIF) \\
\hline Curvature & -0.04 & 0.983 & 1.017 \\
Elevation & 0.804 & 0.441 & 2.267 \\
Flow Accumulation & 0.222 & 0.957 & 1.045 \\
Groundwater Depth & 0.006 & 0.485 & 2.062 \\
LULC & 0.159 & 0.947 & 1.056 \\
NDVI & -1.198 & 0.925 & 1.081 \\
Rainfall & -0.148 & 0.652 & 1.534 \\
Slope & 0.769 & 0.608 & 1.644 \\
Soil Texture & 0.106 & 0.58 & 1.724 \\
Distance to Stream & 1.73 & 0.61 & 1.641 \\
Stream Density & -0.095 & 0.65 & 1.538 \\
Constant & -4.383 & &
\end{tabular}

\section{AHP Pairwise Comparison Matrix Results}

After reclassifying and ranking the eleven-flood factor thematic raster into subclasses, the pairwise comparison was performed for $5 \times 5,8 \times 8,4 \times 4$, and $3 \times 3$ matrixes using the AHP calculator (Table 3), where the diagonal element is equal to 1. As indicated in Table 3, the significance of sub-criteria for each factor has shown in the row of the pairwise comparison matrix. The first row in Table 3 illustrates the significance of the first slope angle compared to the other slope angle classes. For instance, the first slope angle class $\left(0^{\circ}-5^{\circ}\right)$ is significantly more important than the other slope classes, which are placed in the column for flood probability and assigned 9. However, the last classes of the slope angle at the row have less significance for flood probability and assigned the reciprocal values of the pairwise comparison (E.g. 1/9 for the last slope class, $29^{\circ}-77^{\circ}$ ). The details for all parameters weight rating have summarized in Table 3 and the consistency of the factor class weight was evaluated using the consistency ratio (CR). When $\mathrm{CR}<0.1$, the weights' consistency is affirmed. As indicated in Table 3, the CR value for all factor classes is less than 0.1 and indicated no weights' inconsistency. Based on the results of the pairwise comparison analysis, as the slope angle, elevation, and groundwater depth increased, the flood 
probability will be decreased and the vise verse. Similarly, as the distance to Riverbed increased, the flood probability will be decreased. Concerning the other parameters, as the stream density, rainfall and flow accumulation increased, the flood probability will be increased (Table 3). The flood occurrence probability and its impact also depend on the hydraulic behavior of soil regard to the other parameters. If the permeability of soil is high, the flood probability will low. This depends on the grain size and diameters of pore space between soil particles. Therefore, the clay soil has low permeability than the high water holding capacity. This is the case why the clay soil has received a high value (9) in the pairwise comparison matrix (Table 3). In the study area, Settlement, bare land, agricultural land, grazing land, water body, and wetland have a high contribution to flood occurrence respectively compared to the forested regions.

Table 3 Pairwise comparison matrix and weight of flood factor classes

\begin{tabular}{|c|c|c|c|c|c|c|c|}
\hline \multirow[t]{2}{*}{ Factors } & \multicolumn{2}{|c|}{ Sub Factor Class(i) } & \multicolumn{5}{|c|}{ Sub Factor Class (j) } \\
\hline & Class & $0^{\circ}-0.5^{\circ}$ & $0.85^{\circ}-11^{\circ}$ & $11^{\circ}-19^{\circ}$ & $19^{\circ}-29^{\circ}$ & $29^{\circ}-77^{\circ}$ & W \\
\hline \multirow{6}{*}{ Slope } & $0^{\circ}-5^{\circ}$ & 1 & 2 & 5 & 7 & 9 & 0.509 \\
\hline & $5^{\circ}-11^{\circ}$ & 0.5 & 1 & 2 & 3 & 4 & 0.229 \\
\hline & $11^{\circ}-19^{\circ}$ & 0.2 & 0.5 & 1 & 2 & 5 & 0.143 \\
\hline & $19^{\circ}-29^{\circ}$ & 0.14 & 0.33 & 0.5 & 1 & 2 & 0.075 \\
\hline & $29^{\circ}-77^{\circ}$ & 0.11 & 0.25 & 0.2 & 0.5 & 1 & 0.044 \\
\hline & Consistency Ra & & & & & & \\
\hline \multirow{7}{*}{ Elevation } & Class (m) & $1,774-1972$ & $1,972-2,220$ & $2,220-2,513$ & $2,513-2,979$ & $2,979-4,037$ & $\mathbf{W}$ \\
\hline & $1,774-1972$ & 1 & 3 & 6 & 7 & 9 & 0.543 \\
\hline & $1,972-2,220$ & 0.33 & 1 & 3 & 3 & 4 & 0.222 \\
\hline & $2,220-2,513$ & 0.17 & 0.33 & 1 & 2 & 5 & 0.123 \\
\hline & $2,513-2,979$ & 0.14 & 0.33 & 0.5 & 1 & 2 & 0.071 \\
\hline & $2,979-4,037$ & 0.11 & 0.25 & 0.2 & 0.5 & 1 & 0.042 \\
\hline & Consistency Ra & & & & & & \\
\hline \multirow{7}{*}{ Flow } & Class & Very low & Low & Moderate & High & Very high & $\mathbf{W}$ \\
\hline & Very low & 1 & 0.33 & 0.11 & 0.11 & 0.11 & 0.031 \\
\hline & Low & 3 & 1 & 0.33 & 0.33 & 0.33 & 0.092 \\
\hline & Moderate & 9 & 3 & 1 & 0.33 & 0.33 & 0.186 \\
\hline & High & 9 & 3 & 3 & 1 & 1 & 0.346 \\
\hline & Very high & 9 & 3 & 3 & 1 & 1 & 0.346 \\
\hline & Consistency Ra & & & & & & \\
\hline \multirow{7}{*}{$\begin{array}{l}\text { Distance } \\
\text { Stream }\end{array}$} & Class (m) & $0-100$ & $100-300$ & $300-500$ & $500-700$ & $700-6,116.5$ & $\mathbf{W}$ \\
\hline & $0-100$ & 1 & 3 & 5 & 9 & 9 & 0.529 \\
\hline & $100-300$ & 0.33 & 1 & 3 & 3 & 5 & 0.229 \\
\hline & $300-500$ & 0.2 & 0.33 & 1 & 3 & 7 & 0.147 \\
\hline & $500-700$ & 0.11 & 0.33 & 0.33 & 1 & 1 & 0.053 \\
\hline & $700-6,116.5$ & 0.11 & 0.2 & 0.14 & 1 & 1 & 0.042 \\
\hline & Consistency Ra & & & & & & \\
\hline \multirow{7}{*}{$\begin{array}{l}\text { Stream } \\
\text { Density }\end{array}$} & Class (Km2) & $0-0.8$ & $0.8-2.1$ & $2.1-3.5$ & $3.5-5.1$ & $5.1-8.8$ & $\mathbf{W}$ \\
\hline & $0-0.8$ & 1 & 0.33 & 0.2 & 0.14 & 0.11 & 0.033 \\
\hline & $0.8-2.1$ & 3 & 1 & 0.33 & 0.2 & 0.14 & 0.064 \\
\hline & $2.1-3.5$ & 5 & 3 & 1 & 0.33 & 0.14 & 0.124 \\
\hline & $3.5-5.1$ & 7 & 5 & 3 & 1 & 1 & 0.324 \\
\hline & $5.1-8.8$ & 9 & 7 & 7 & 1 & 1 & 0.455 \\
\hline & Consistency Ra & & & & & & \\
\hline \multirow{5}{*}{ NDVI } & Class & Very Low & Low & Moderate & High & Very High & $\mathbf{W}$ \\
\hline & Very Low & 1 & 2 & 5 & 9 & 9 & 0.489 \\
\hline & Low & 0.5 & 1 & 3 & 5 & 7 & 0.282 \\
\hline & Moderate & 0.2 & 0.33 & 1 & 3 & 7 & 0.144 \\
\hline & High & 0.11 & 0.2 & 0.33 & 1 & 1 & 0.047 \\
\hline
\end{tabular}




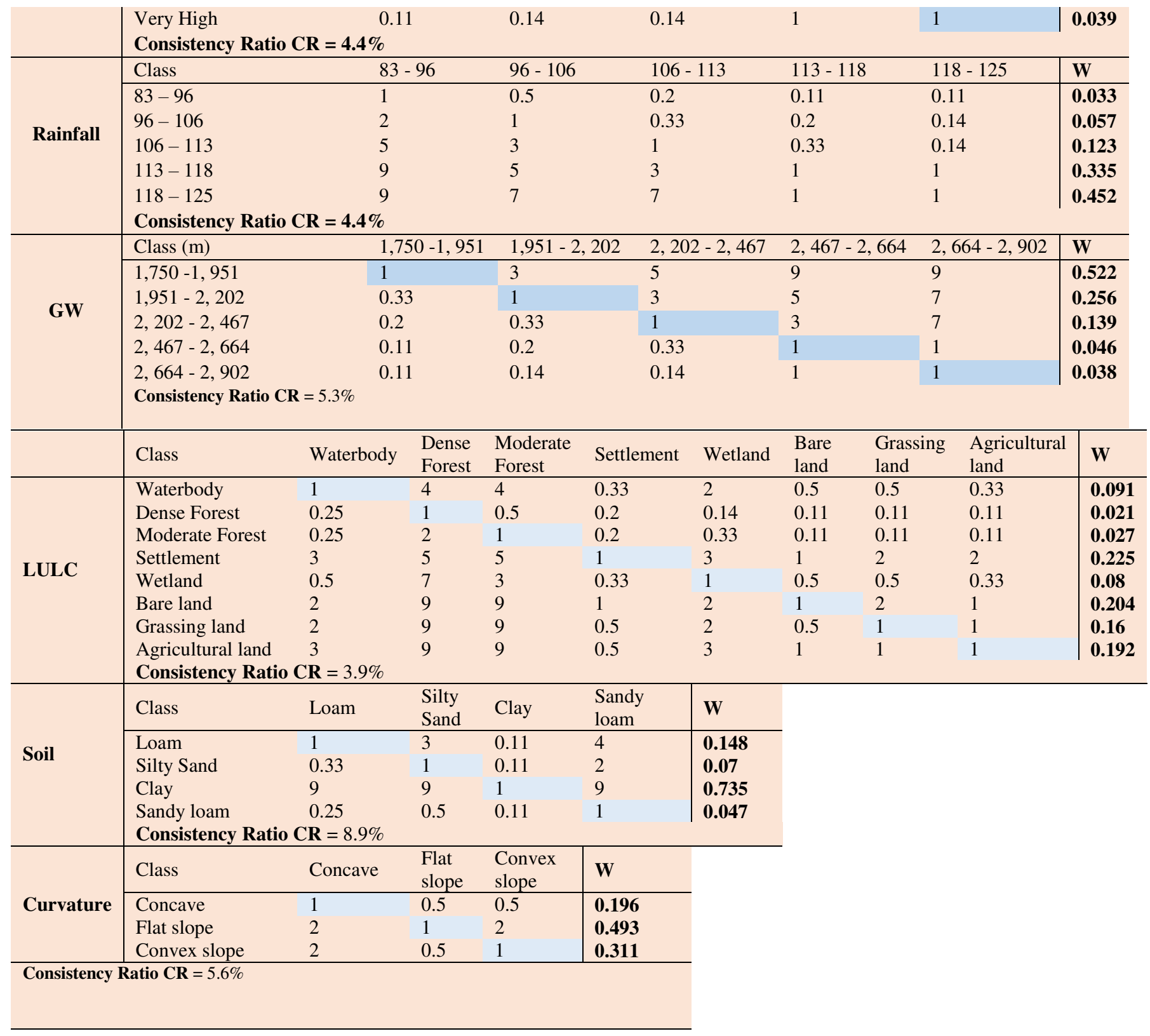

\section{Flood Susceptibility Model}

\section{Frequency Ratio Flood Susceptibility model}

After weight rating for each flood driving factor classes using FR, each flood-driving factor was converted into raster using lookup in spatial analysis option under ArcGIS 10.2 software. The flood Susceptibility index of the study area is generated by sum up all raster maps carefully using the raster calculator in spatial analysis. The flood susceptibility index (Fig. 5) was reclassified into five classes (Very low, low, moderate, high, and very high) using the natural break method in ArcGIS as shown in Eq. 6. As a result, shown in Table 4, high and very high flood susceptibility classes have covered $19.8 \%$ and 20.7 $\%$ of the study area, respectively. However, the remaining, $14.1 \%, 23.6 \%$, and $21.7 \%$ of the study area covered by very low, low, and moderate flood susceptibility areas. The high and very high flood susceptibility classes in the study area fell 
closer to the Ribb River, Gumara River, Ribb dam, and other streams as well as flat and impervious soil regions. However, the low and very low regions fell in the steep slope gradient and deep groundwater depth as well as densely forested and previous regions.

$F S I=F R *$ Slope raster $+F R *$ Stream density raster $+F R *$ Slope curvature raster $+F R *$ Soil Texture raster $+F R *$ Land use raster $+F R^{*}$ Distance to stream raster $+F R^{*}$ Flow Accumulation $+F R^{*}$ Groundwater depth raster $+F R^{*}$ Elevation raster $+F R^{*} N D V I$ raster $+F R^{*}$ Rainfall raster.

\section{Information Value Flood Susceptibility Model}

Similar to the frequency ratio method, the flood susceptibility index generated using the information value method (Fig. 6) was reclassified into five classes (Very low, low, moderate, high, and very high) using the natural break method in ArcGIS as shown in Eq. 2. As a result, shown in Table 4, high and very high flood susceptibility classes have covered $20.3 \%$ and $20.2 \%$ of the study area, respectively. However, the remaining, $13.1 \%, 23.9 \%$, and $22.5 \%$ of the study area covered by very low, low, and moderate flood susceptibility areas.

$F S I=I V *$ Slope raster $+I V *$ Stream density raster $+I V *$ Slope curvature raster $+I V *$ Soil Texture raster $+I V^{*}$ Land use raster $+I V^{*}$ Distance to stream raster $+I V^{*}$ Flow Accumulation + $I V^{*}$ Groundwater depth raster $+I V^{*}$ Elevation raster $+I V^{*} N D V I$ raster $+I V^{*}$ Rainfall raster

\section{Logistic Regression Flood Susceptibility Model}

In the logistic regression method, logistic regression coefficients for individual factor was determined using SPSS. The linear combination of LR constant and factor products with LR coefficients is called Z, which is calculated as shown in Eq. 4. The value of Z enters into Eq. 3 and the flood probability index $(\mathrm{P})$ was generated. The value of $\mathrm{P}$ ranges from $0-1$ and the closer the value to one is indicating the higher the flood susceptibility region. Similar to the frequency ratio and information value methods, the flood susceptibility index generated using the logistic regression method (Fig. 7) was reclassified into five classes (Very low, low, moderate, high, and very high) using the natural break method in ArcGIS as shown in Eq. 3. As a result, shown in Table 4, high and very high flood susceptibility classes have covered $13.2 \%$ and $9.3 \%$ of the study area, respectively. However, the remaining, $54.3 \%, 11.2 \%$, and $12.1 \%$ of the study area covered by very low, low, and moderate flood susceptibility area.

$Z=-4.38+0.769 *$ Slope raster $+-0.095 *$ Stream density raster $+-0.040 *$ Slope curvature raster $+0.106 *$ Soil Texture raster $+0.159 *$ Land use raster $+1.73 *$ Distance to stream raster 
$+0.222 *$ Flow Accumulation $+0.006 *$ Groundwater depth raster $+0.804 *$ Elevation raster +$1.198 * N D V I$ raster $+-0.148 *$ Rainfall raster

\section{Analytical Hierarchy Process Flood Susceptibility Model}

Similar to the frequency ratio and information value methods, the flood susceptibility index generated using the analytical hierarchy process method (Fig. 8) was reclassified into five classes (Very low, low, moderate, high, and very high) using the natural break method in ArcGIS as shown in Eq. 9. As a result, shown in Table 4, high and very high flood susceptibility classes have covered $19.8 \%$ and $10.2 \%$ of the study area, respectively. However, the remaining, $19.7 \%, 24.8 \%$, and $25.6 \%$ of the study area covered by very low, low, and moderate flood susceptibility areas.

$$
\begin{aligned}
& L S I=W * \text { Slope raster }+W * \text { drainage density }+W * \text { groundwater depth }+W \\
& \quad * \text { rainfall }+W * N D V I+W * \text { flow accumlation }+W * \text { aspect raster }+W \\
& \quad * \text { curvature raster }+W * \text { soil raster }+W * \text { Land use raster }+W \\
& \quad * \text { distance to stream raster }
\end{aligned}
$$

\begin{tabular}{|c|c|c|c|c|c|c|c|c|c|c|}
\hline IVFSI & Class & IVFSP & $\%$ FSM & VFP & $\% \mathrm{VF}$ & LRFSI & LRFSP & $\%$ FSM & VFP & $\% \mathrm{VF}$ \\
\hline$-25--15.1$ & Very low & 3226367 & 13.1 & 13 & 0.01 & $0-0.1$ & 13381271 & 54.3 & 627 & 0.34 \\
\hline$-15.1--10$ & Low & 5901361 & 23.9 & 472 & 0.26 & $0.1-0.3$ & 2756345 & 11.2 & 4470 & 2.46 \\
\hline$-10--5$ & Moderate & 5535540 & 22.5 & 4816 & 2.65 & $0.3-0.5$ & 2972834 & 12.1 & 15071 & 8.28 \\
\hline$-5-1.2$ & High & 4996851 & 20.3 & 21844 & 12.00 & $0.5-0.7$ & 3243717 & 13.2 & 61228 & 33.64 \\
\hline $1.2-13$ & Very high & 4982782 & 20.2 & 154863 & 85.09 & $0.7-1$ & 2288737 & 9.3 & 100612 & 55.28 \\
\hline FRFSI & Class & FRFSP & $\%$ FSM & VFP & $\%$ VF & Methods & \multicolumn{2}{|c|}{$\begin{array}{c}\text { Success Rate Curve, } \\
\text { AUC \% } \\
\end{array}$} & \multicolumn{2}{|c|}{$\begin{array}{c}\text { Prediction Rate Curve } \\
\text { AUC \% } \\
\end{array}$} \\
\hline $4-9$ & Very low & 3480969 & 14.1 & 15 & 0.01 & LR & \multicolumn{2}{|c|}{75.6} & \multicolumn{2}{|c|}{81.4} \\
\hline $9-14$ & Low & 5825312 & 23.6 & 511 & 0.28 & FR & \multicolumn{2}{|c|}{97.9} & \multicolumn{2}{|c|}{99.1} \\
\hline $14-19$ & Moderate & 5356987 & 21.7 & 4775 & 2.62 & & \multirow{2}{*}{\multicolumn{2}{|c|}{71}} & \multirow{2}{*}{\multicolumn{2}{|c|}{78.2}} \\
\hline $19-27$ & High & 4874089 & 19.8 & 21635 & 11.89 & IV & & & & \\
\hline $27-46$ & Very high & 5105544 & 20.7 & 155072 & 85.20 & & \multirow{2}{*}{\multicolumn{2}{|c|}{82.5}} & \multirow{2}{*}{\multicolumn{2}{|c|}{86.9}} \\
\hline AHPFSI & Class & AHPFSP & \%FSM & VFP & $\% \mathrm{VF}$ & AHP & & & & \\
\hline $0.5-1.7$ & Very low & 4849344 & 19.7 & 0 & 0.00 & & & & & \\
\hline $1.7-2.3$ & Low & 6122024 & 24.8 & 12 & 0.01 & & & & & \\
\hline $2.3-2.9$ & Moderate & 6298368 & 25.6 & 558 & 0.31 & & & & & \\
\hline $2.9-3.6$ & High & 4887029 & 19.8 & 10491 & 5.76 & & & & & \\
\hline $3,6-5.3$ & Very high & 2486139 & 10.1 & 170947 & 93.92 & & & & & \\
\hline
\end{tabular}

Table 4 Statistical model summary of FR, LR, IV, and AHP methods

Note: AHPFSI is analytical hierarchy process flood susceptibility index, IVFSI is information value flood susceptibility index, IVFSP is information value flood susceptibility pixel, FSM is flooded susceptibility map, VFP is validation flood pixel, VF is validation flood, LRFSI 
is logistic regression flood susceptibility index, LRFSP is logistic regression flood susceptibility pixel, FRFSI is frequency ratio flood susceptibility index, FRFSP is frequency ratio flood susceptibility pixel

\subsection{Model Validation and Comparison}

The most important ambition of flood susceptibility mapping is to determine the areas that are prone to flood hazards. However, flood susceptibility modeling without prediction and model performance evaluation is non-sense to the application of disaster reduction programs. Although researchers used many techniques to validate the flood susceptibility model, the receiver operating characteristics (ROC) method is routinely used (Shafizadeh et al. 2018; Tehrany et al. 2013; Liuzzo et al. 2019) because of its simplicity and produce clear as well as reliable results (Samanta et al., 2018; Rhmati et al. 2016; Khosravi et al. 2016; Pradhan and Lee 2010). Therefore, the prediction and model performance of the flood susceptibility map of the study area was validated by comparing the flood model with existing flood data using the ROC curve (Lee et al. 2007; Tien Bui et al. 2012; Pourghasemi et al. 2012). The prediction accuracy and model performance of the flood susceptibility map was evaluated quantitatively using the receiver operating characteristics (ROC) curve based on the evaluation of the true and false positive rates (Chauhan et al. 2010; Mahyat et al. 2019). Both the training and testing dataset were used to calculate the success rate curve and predictive rate curve. The predictive rate curve for the four models was obtained by comparing testing flood datasets with the flood susceptibility index while the success rate curve was also obtained for the four models by comparing training flood datasets. The AUC value ranges from $0.5-1$ (Yesilnacar and Topal, 2005) and the closer the value to one indicating the higher accuracy of the model. As the results of the Success rate curve of AUC analysis indicated in (Table 4 and Fig. 9), FR has received a $97.9 \%$ and $99.1 \%$ success rate curve and prediction rate curve, respectively. When evaluating the accuracy of the model, the FR model indicated superior performance (97.9\%), followed by the AHP model (82.5\%), LR model (75.6\%), and then the IV model $(71 \%)$. Similarly, the model has the greatest prediction capacity $(99.1 \%)$, followed by the AHP model (86.9\%), LR model (81.4\%) and the IV model has 78.2\%. From the AUC results, the FR model indicating, the highest model accuracy and prediction capacity but the IV model has indicated relatively less model accuracy and predictive capacity in the present study. Moreover, the four models (FR, AHP, LR, and IV) resulted in AUC > 75\% which is good, very good, and excellent model performance (Yesilnacar and Topal 2005), respectively. This finding is similar to the work of (Bui et al. 2018; Samanta et al. 2018a; Rahman et al. 2019). Besides the ROC curve, 
flood-testing datasets that are not used for model development were overlaid on the four flood susceptible maps. The number of flood points that fells in the very high susceptibility class was measured as shown in Table 4, 85.2\%, 55.3\%, 85.1\%, and 93.92\% of flood points were fell in the very high susceptibility class of FR, LR, IV, and AHP models. Here also the FR and AHP models confirm again its excellent performance followed by the IV model. All in all the flood points which fell in the very high susceptibility class are greater than 55\%, indicating acceptable model accuracy of IV, LR, AHP, and FR models.

Although the analytical hierarchy process, frequency ratio, information value, and logistic regression methods are routinely used methods for flood susceptibility mapping, they have some foreseeable limitations. For example, the logistic regression model can perform multivariate statistical analysis between a dependent variable and a set of independent variables (Table 2), but it is incapable to analyze the impacts of internal classes of flood governing factors individually on flood occurrence. As the results indicated in Table 2, the importance of flood driving factors is determined using the LR model. The result showed that among eleven factors, distance to stream (1.73), elevation (0.8), slope gradient (0.769), flow accumulation (0.222), land use (0.159), soil texture (0.106), and groundwater depth (0.006) had received the highest statistical impact on the probability of flood occurrence (Table 2). These are in line with the finding of Kia et al. 2012; Chapi et al. 2017; Mosavi et al. 2018; Falah et al. 2019; Rahman et al. 2019). Overall, logistic regression also causes oversimplification and generalization on the effects of flood governing factors. Whereas frequency ratio and information value are simple and effective statistical methods that can extract the influence of each flood governing factor class on flood occurrence (Table 1), but it cannot consider the relationship between these flood governing factors and flood occurrence. The analytical hierarchy process method is a very important method to evaluate the effects of factors and factor classes on flood occurrence probability, however, this method has a series of subjectivity problems during pairwise comparison to assign the weights for each factor class and flood driving factors. In summary, there are no unique statistical and expert-based methods to determine both the effects of each factor class and general effects of flood factors. Therefore, the combination use of bivariate and multivariate statistical methods to predict flood susceptibility in a region is very essential when there is no unique method that helps to evaluate the effects of flood driving factors as general and inherently. 
In literature, comparison among information value, logistic regression, frequency ratio, and analytical hierarchy process method was not performed rather than the frequency ratio method with the information value method, logistic regression method with information value and frequency methods, the AHP method with the information value method, and the AHP method with the frequency ratio method. (Chen et al. 2016) states that the prediction rate of $83.69 \%$ using the frequency ratio model is better than the prediction rate of $81.22 \%$ using the information value method. This finding is similar to the present study, the frequency ratio method showed better performance for both success rates $(\mathrm{AUC}=97.9 \%)$ and predictive rate curve $(\mathrm{AUC}=99.1 \%)$ than the information value method with success rate curve $(\mathrm{AUC}=71.0 \%)$ and predictive rate curve $(\mathrm{AUC}=78.2 \%)$. As shown from the work of (Mahyat et al. 2018), the logistic regression model showed a high predictive accuracy of AUC value of $79.45 \%$ compared to the frequency ratio and information value model with prediction rate curve value $(\mathrm{AUC}=67.33 \%$ for $\mathrm{FR}, \mathrm{AUC}=78.18 \%$ for IV). Nevertheless, in the present model, the frequency model showed a relatively few difference in prediction rate value $(\mathrm{AUC}=99.1 \%)$ than the information value and logistic regression models with prediction rate value $(\mathrm{AUC}=78.2 \%$ for $\mathrm{IV}, \mathrm{AUC}=81.4 \%$ for $\mathrm{LR})$. From the work of (Khosravi et al. 2016), based on the predictive rate value of the area under the receiver operating characteristic curve (AUC), the frequency ratio (FR) and analytical hierarchy process (AHP) models showed a little bit different in predictive capacity, which is $96.57 \%$ for the FR model and $94.92 \%$ for the AHP model. This result is in line with the present work, the prediction rate of $99.1 \%$ using the frequency ratio model is better performance than the prediction rate curve $86.9 \%$ for the AHP model. Rahman et al. (2019) found that the logistic regression model $(\mathrm{AUC}=86.8 \%$ ) gave a more realistic flood susceptibility map than the frequency ratio (AUC= $85.6 \%)$ and AHP $(\mathrm{AUC}=64 \%)$ model. However, this result is not in line with the present work which is the frequency ratio is better than AHP and the logistic regression model. This difference happens mostly due to the number of and types of input parameters for model construction. Generally, the AHP, bivariate, and multivariate statistical methods in literature and this study showed, the closer prediction capacity with AUC > 64\% and AUC > 75\%, respectively fell in the range of good and very good/excellent performance (Yesilnacar and Topal, 2005). The flood validation results for the four models (FR, LR, IV \& AHP) are closer to each other. Therefore, from these results, the research work finds out that in flood susceptibility mapping, the four models have equal potential to generate flood-prone areas but factor selection should be playing a more 
important role than the methods. Although all statistical models indicated higher prediction accuracy, based on their statistical significance analysis result of AUC value (see Table 4 ), the frequency ratio (FR) model is better than the analytical hierarchy process (AHP), logistic regression (LR) model, and information value model for regional land use planning, flood hazard mitigation, and prevention purposes.

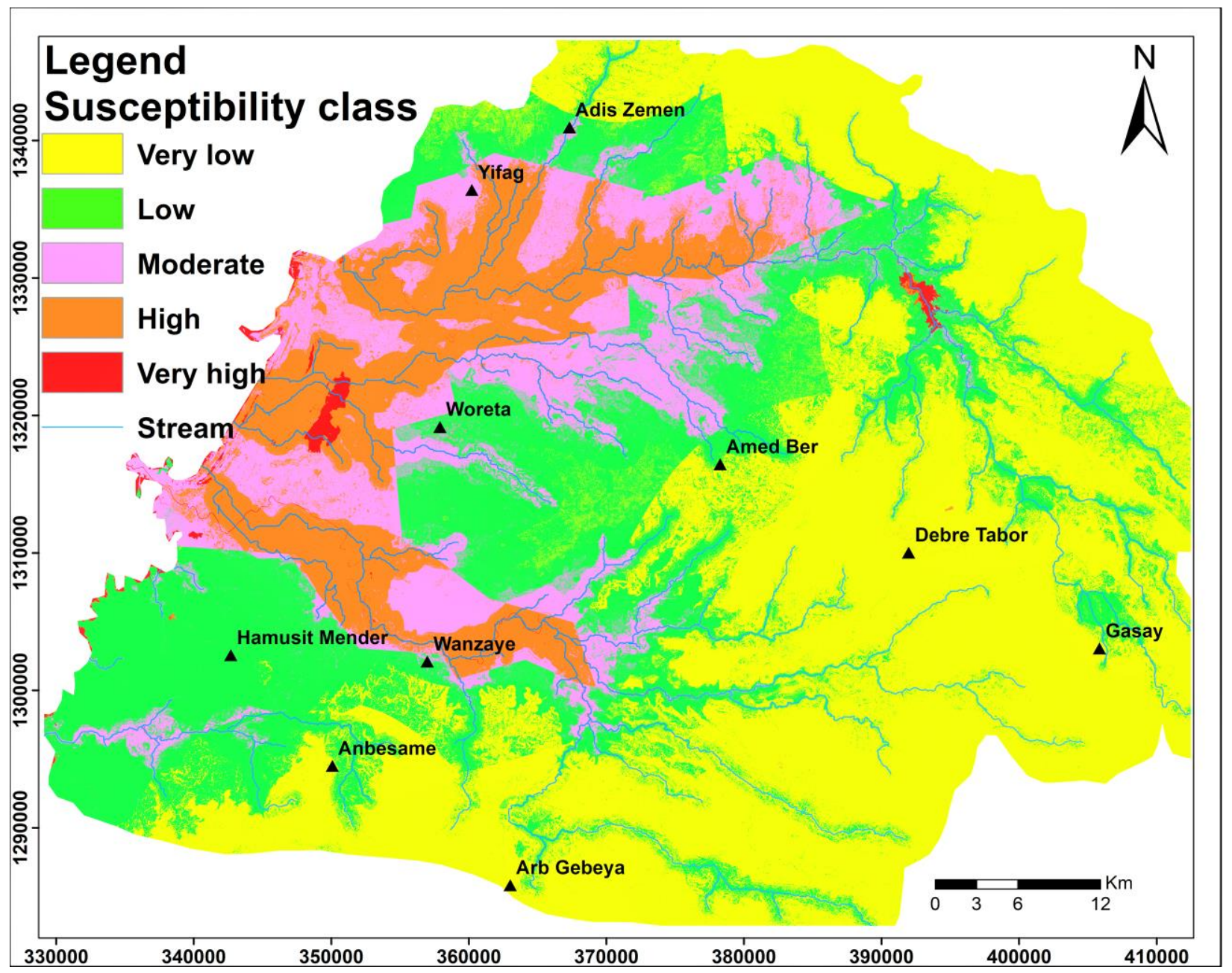

Figure 5 Flood Susceptibility map using the frequency ratio method 


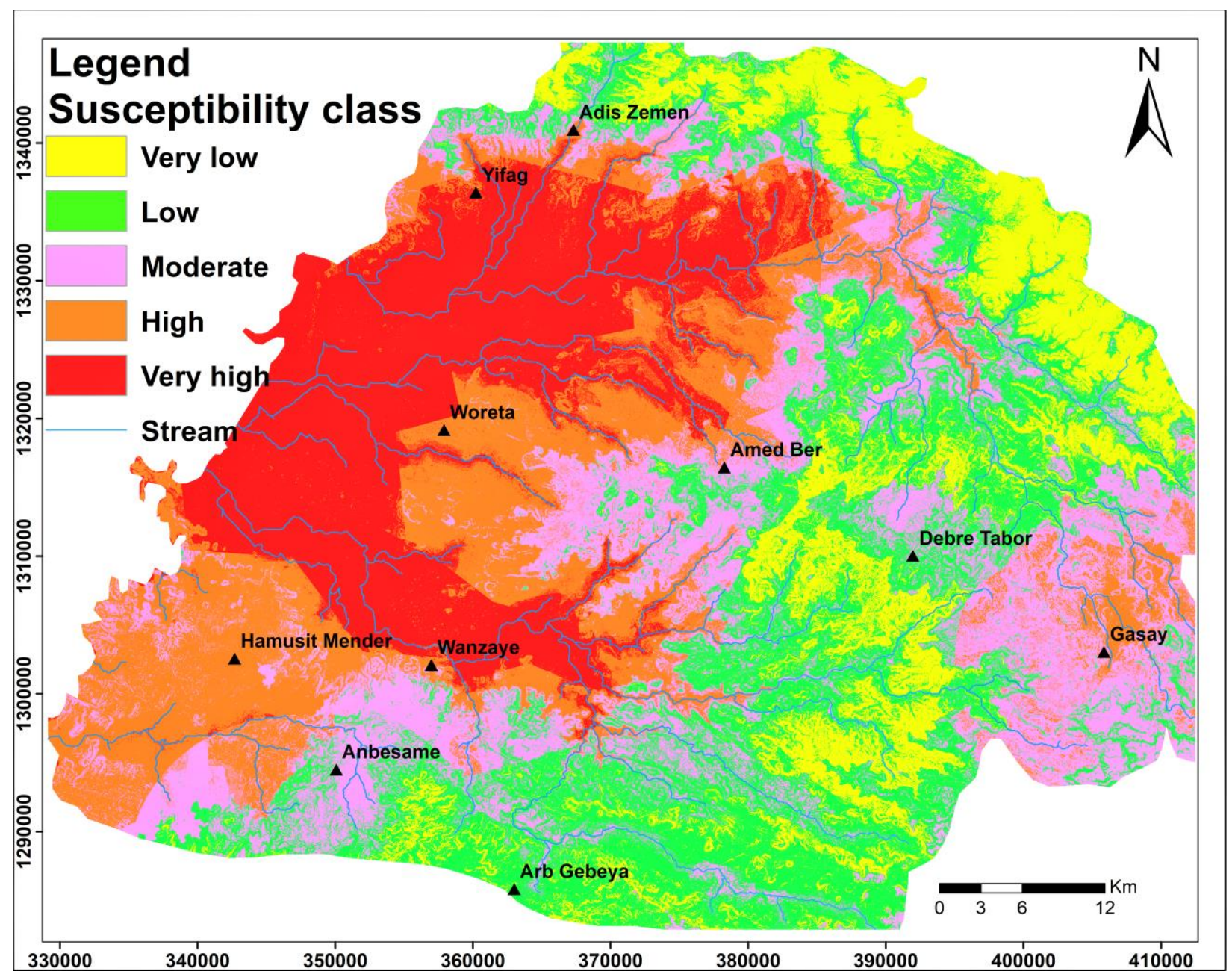

Figure 6 Flood Susceptibility map using information value method 


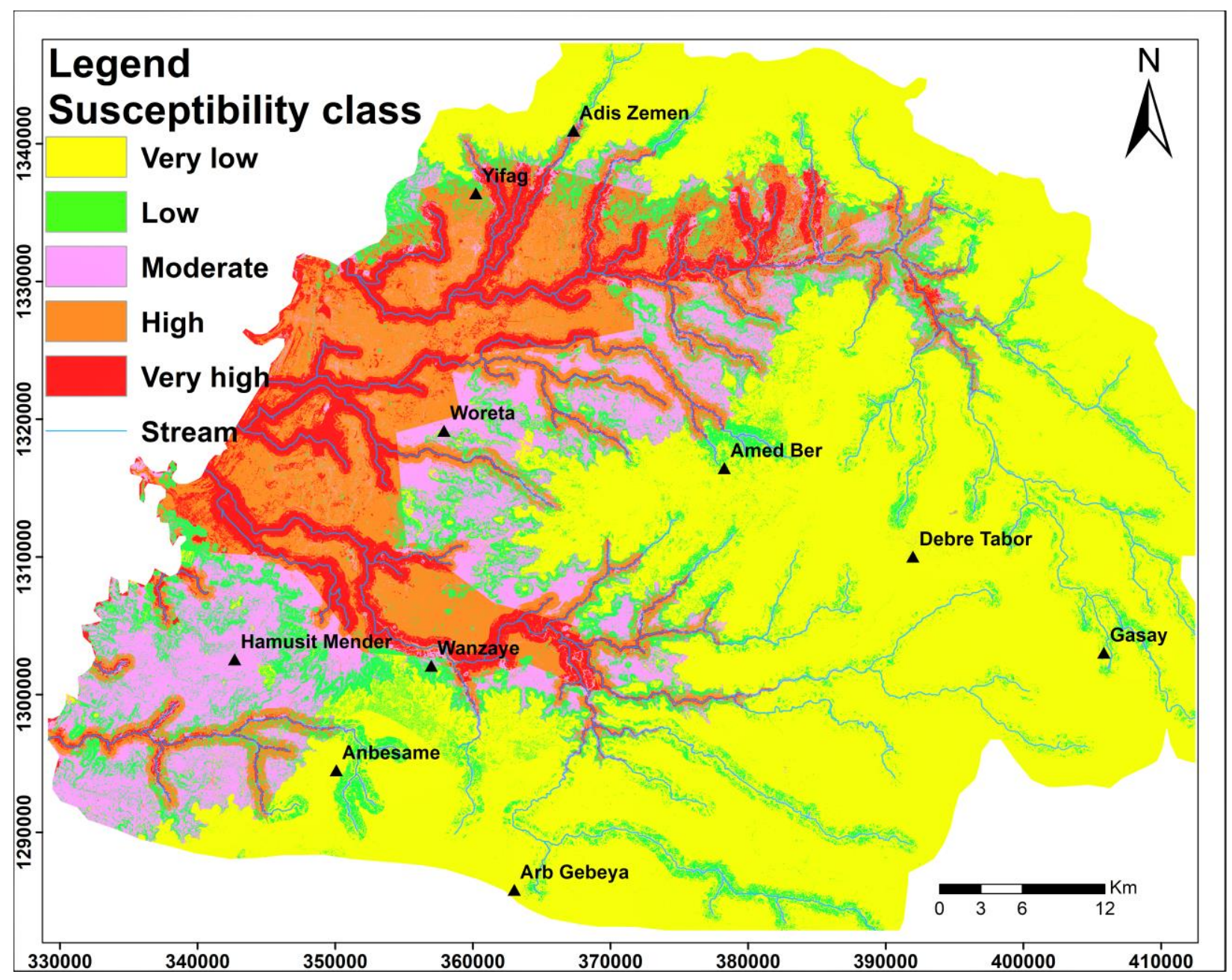

Figure 7 Flood Susceptibility map using the logistic regression method 


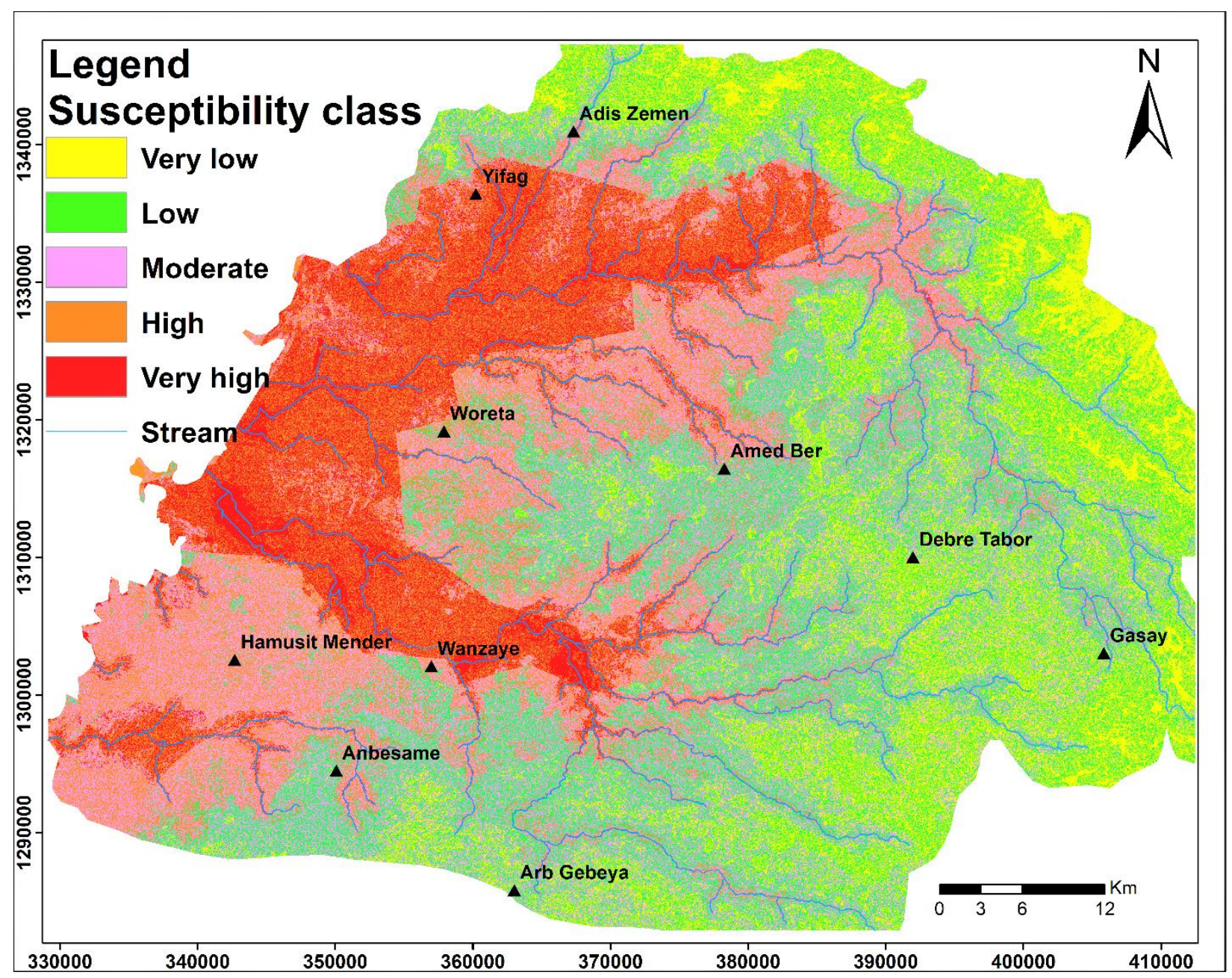

Figure 8 Flood Susceptibility map using analytical hierarchy process method 

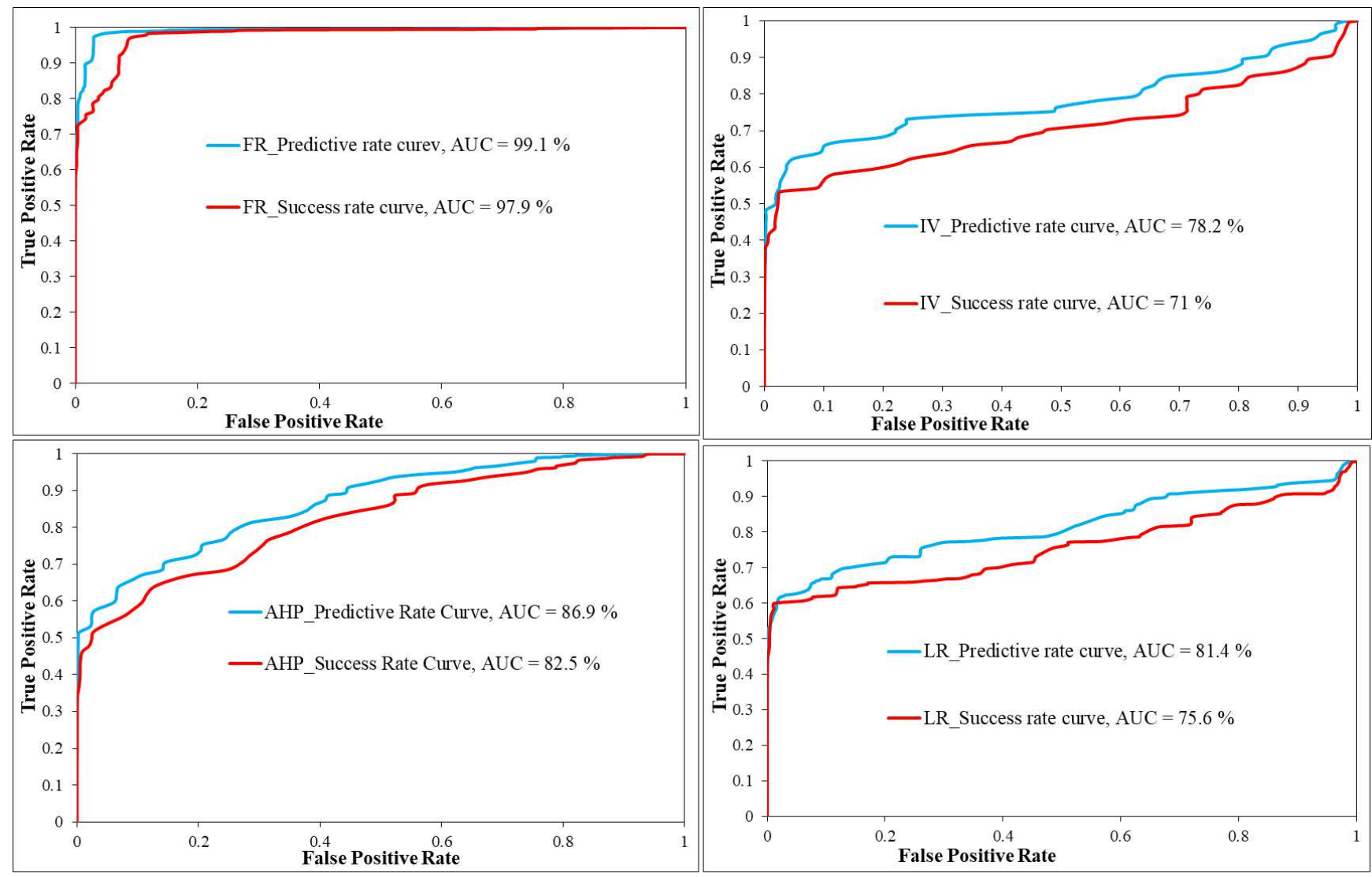

Figure 9 Predictive and success rate curves for IV, LR, FR, and AHP methods

\section{Conclusion}

In flood hazard reduction and mitigation management, a flood susceptibility map is one of the key elements. Therefore, it is essential to prepare the most precise and reliable flood susceptibility map. The application of frequency ratio, information value, logistic regression, and analytical hierarchy process (AHP) models have been tested in flood susceptibility mapping and their results are compared to each other using AUC results. The results showed that the flood susceptibility map produced by the frequency ratio method is relatively better than the AHP, logistic regression, and information value methods. However, the ranges of prediction accuracy value for all four methods are indicated that the frequency ratio, AHP, logistic regression, and information value methods are capable to produce an acceptable flood susceptibility model. The models, which are generated using the bivariate, multivariate statistical, and AHP models, can help to understand the flood hazard problems in the study area. Although the resulting maps cannot forecast the time, and how often it can occur, it has provided the spatial distribution of flood probability. These models can also provide important information to the researchers, local people, 
government, and planners to reduce the flood hazard problems in the study area. Therefore, the concerned bodies may at the Wereda/District, Zone, Region, and Federal levels take tangible activities to mitigate the flood problem by avoiding permanent activities at the high and very high regions with the integration of construction of check dams for streams.

\section{Author contributions}

Azemeraw Wubalem has conceptualized statistical analysis and done the completed modeling analysis. Azemeraw Wubalem wrote the original drafts, which was reviewed and edited by all coauthors. All authors have their contributions to writing the manuscript.

\section{Competing interest}

We declare that we do not any conflict of interest.

\section{Acknowledgments}

We would like to thank the University of Gondar for financial and equipment supports. We also would like to thank all contributing project partners. We also want to give our special thanks to the West Amhara Meteorological Agency, Amhara Water Well Drilling Enterprise, and Ethiopian Mapping Agency. 


\section{Reference}

Adger N.W (2006) Vulnerability, Glob. Environ. Chang. 16:268-281

Ayalew L, Yamagishi H (2005) The application of GIS-based logistic regression for landslide susceptibility mapping in the Kakuda- Yahiko Mountains, Central Japan. Geomorphology $65: 15-31$

Bednarik M, Yilmaz I, Marschalko M (2012) Landslide hazard and risk assessment: a case study from the Hlohovec-Sered' landslide area in south-west Slovakia. Nat Hazards, DOI:10.1007/s11069-012-0257-7

Calil J, Beck MW, Gleason M, Merrifield M, Klausmeyer K, Newkirk S (2015) Aligning natural resource conservation and flood hazard mitigation in California. PLoS One 10: 1-14, https://doi.org/10.1371/journal.pone.0132651 PMID: 26200353

Cao C, Xu P, Wang Y, Chen J, Zheng L, Niu C (2016) Flash flood hazard susceptibility mapping using frequency ratio and statistical index methods in coalmine subsidence areas. Sustainability 8(9): 948

Celikyilmaz A, Turksen IB (2009) Modeling uncertainty with fuzzy logic. Stud Fuzziness Soft Comput 240:149-215

Chandak P.G., Sayyed S.S., Kulkarni Y.U., Devtale M.K (2016) Landslide hazard zonation mapping using information value method near Parphi village in Garhwal Himalaya. Ljemas $4: 228-236$

Chapi K, Singh VP, Shirzadi A, Shahabi H, Bui DT, Pham BT, Khosravi K (2017) A novel hybrid artificial intelligence approach for flood susceptibility assessment. Environ Modell Softw 95:229-245

Chau K. T, Chan J. E (2005) The regional bias of landslide data in generating susceptibility maps using logistic regression: Case of Hong Kong Island. Landslide 2: 280-290

Chauhan S, Sharma M, Arora MK (2010) Landslide susceptibility zonation of the Chamoli region, Garhwal Himalayas, using a logistic regression model. Landslides 7: 411-423 
Chen Z, Wang J (2007) Landslide hazard mapping using a logistic regression model in Mackenzie Valley, Canada. Nat. Hazards 42:75-89

Chen Z and Wang J (2007) Landslide hazard mapping using a logistic regression model in Mackenzie Valley, Canada. Nat. Hazard 42(1): 75-89

Cho S, Kim J, Heo E (2015) Application of fuzzy analytic hierarchy process to select the optimal heating facility for Korean horticulture and stockbreeding sectors. Renew Sustain Energy Rev 49:1075-1083

Dai F. C and Lee C. F (2002) Landslide characteristics and slope instability modeling using GIS, Lantau Island, Hong Kong. Geomorphology 42: 213-228

Das G, Lepcha K (2019) Application of logistic regression (LR) and frequency ratio (FR) models for landslide susceptibility mapping in Relli Khola river basin of Darjeeling Himalaya India. SN Appl Sci 1:1453, https ://doi.org/10.1007/s4245 2-019-1499

Donati L and Turrini M. C (2002) An objective method to rank the importance of the factors predisposing to landslides with the GIS methodology applied to an area of the Apennines (Valnerina; Perugia, Italy). Engg. Geol 63:277-289

Duman T.Y., Can T, Gokceoglu C., Nefesliogocu H. A and Sonmez H (2006) Application of logistic regression for landslide susceptibility zoning of Cekmee area, Istanbul, Turkey. Verlag $242-256$

Falah F, Rahmati O, Rostami M, Ahmadisharaf E, Daliakopoulos IN, Pourghasemi HR (2019) Artificial neural networks for food susceptibility mapping in data-scarce urban areas. In: Pourghasemi HR, Gokceoglu C (eds) Spatial modeling in GIS and R for the earth and environmental sciences. Elsevier 323-336

Hong H, Junzhi L, A-Xing Z (2020) Modeling landslide susceptibility using logit Boost alternating decision trees and forest by penalizing attributes with the bagging ensemble. Science of the Total Environment 718:3-15, https://doi.org/10.1007/s00477-012-0598-5 
Jacinto R., Grosso N., Reis E., Dias L., Santos F.D., Garrett P (2015) Continental Portuguese Territory Flood Susceptibility Index - Contribution to a vulnerability index. Nat. Hazards Earth Syst. Sci 15:1907-1919

Khosravi K, Nohani E, Maroufinia E, Pourghasemi HR (2016) A GIS-based flood susceptibility assessment and its mapping in Iran: a comparison between frequency ratio and weights-of evidence bivariate statistical models with multi-criteria decision-making technique. Nat Hazards 83: 1-41

Kia MB, Pirasteh S, Pradhan B, Mahmud AR, Sulaiman WNA, Moradi A (2012) An artificial neural network model for flood simulation using GIS: Johor River Basin, Malaysia. Environ Earth Sci 67: 251-264, https://doi.org/10.1007/s12665-011-1504-Z

Kouhpeima S., Feizniab H., Ahmadib Moghadamniab A.R (2017) Landslide susceptibility mapping using logistic regression analysis in Latyan catchment. Desert 85 - 95

Lee MJ, Kang JE, Jeon S (2012) Application of frequency ratio model and validation for predictive flooded area susceptibility mapping using GIS. In Geoscience and Remote Sensing Symposium (IGARSS), IEEE International, Munich 895-898

Lee M-J, Kang J-e, Jeon S (2012) Application of frequency ratio model and validation for predictive flooded area susceptibility mapping using GIS. Proceedings of the Geoscience and Remote Sensing Symposium (IGARSS), Jul 22-27; Munich (Germany): IEEE International 4 Lee S, Pradhan B (2007) Landslide hazard mapping at Selangor, Malaysia using frequency ratio and logistic regression models. Landslides 4: 33-41

Lee S, Sambath T (2006) Landslide susceptibility mapping in the Damrei Romel area, Cambodia using frequency ratio and logistic regression models. Environ. Geol 50: 847- 855

Lee S, Talib JA (2005) Probabilistic landslide susceptibility and factor effect analysis. J Environ Geol 47: 982-990

Liuzzo L, Sammartano V, Freni G (2019) Comparison between Different Distributed Methods for Flood Susceptibility Mapping. Water Resour Manag 33: 3155-3173, https://doi.org/10.1007/s11269-01902293-w 
Luelseged Ayalew and Yamagishi H (2005) The application of GIS-based logistic regression for landslide susceptibility mapping in the Kakuda- Yahiko Mountains, Central Japan. Geomorphology 65:15 - 31

Luu C, Von Meding J, Kanjanabootra S (2018) Assessing food hazard using food marks and analytic hierarchy process approach: a case study for the 2013 food event in Quang Nam, Vietnam. Nat Hazards 90:1031-1050

Mahyat Shafapour, Tehrany Lalit, Kumar Mustafa, Neamah Jebur, Farzin Shabani (2019) Evaluating the application of the statistical index method in flood susceptibility mapping and its comparison with frequency ratio and logistic regression methods. Geomatics, Natural Hazards and Risk 10: 1 79-101, DOI: 10.1080/19475705.2018.1506509

Meten M., Bhandary N.P and Yatabe R (2015) GIS-based frequency ratio and logistic regression modeling for landslide susceptibility mapping of Debre Sina area in central Ethiopia. J.Mt.Sci 12(6): $1355-1372$

Mosavi A, Ozturk P, Chau K-w (2018) Flood prediction using machine learning models: literature review. Water 10: 1536

Nguyen AT, Nguyen LD, Le-Hoai L, Dang CN (2015) Quantifying the complexity of transportation projects using the fuzzy analytic hierarchy process. Int J Project Manage 33:1364-1376

Ohlmacher GC, Davis JC (2003) Using multiple logistic regression and GIS technology to predict landslide hazard in northeast Kansas, USA. Eng Geol 69: 331-343

Pham BT, Prakashi I, Singh S.K, Shizardi A, Shahabi H, Bui D.T (2019b) Landslide susceptibility modeling using reduce error pruning trees and different ensemble techniques: hybrid machine learning approach. Catena 175:203-218

Pourghasemi HR, Pradhan B, Gokceoglu C (2012) Application of fuzzy logic and analytical hierarchy process (AHP) to landslide susceptibility mapping at Haraz watershed. Iran Nat Hazards 63: 965-996 
Pradhan B, Mansor S, Pirasteh S, Buchroithner M (2011) Landslide hazard and risk analyses at a landslide-prone catchment area using the statistical-based geospatial model. Int J Remote Sens 32(14):4075-4087, DOI:10.1080/01431161.2010.484433

Pradhan B., Lee S (2010) Landslide susceptibility assessment and factor effect analysis: backpropagation artificial neural networks and their comparison with frequency ratio and bivariate logistic regression modeling. Environmental Modelling \& Software 25, 747-759

Rahman M, Chen Ningsheng, Md Monirul Islam, Ashraf Dewan, Javed Iqbal Rana, Muhammad Ali, Washakh Tian, Shufeng (2019) Flood Susceptibility Assessment in Bangladesh Using Machine Learning and Multicriteria Decision Analysis. Earth Systems and Environment 3: 585-601, https://doi.org/10.1007/s41748-019-00123-y

Rahmati O, Pourghasemi HR (2017) Identification of critical flood-prone areas in data-scarce and ungauged regions: a comparison of three data mining models. Water Resour Manag 31(5):1473-1487

Rahmati O, Pourghasemi HR, Zeinivand H (2016) ls in the Golastan Province, Iran. Geocarto Int., 31: 42-70, https://doi. org/10.1080/10106049.2015.1041559

Regmi A.D., Yoshida K., Pourghasemi H.R., Dhital M.R., Pradhan B (2014) Landslide susceptibility mapping along Bhalubang-Shiwapur area of mid-western Nepal using frequency ratio and conditional probability models. Jour. Mountain Sci 11(5): 1266-1285

Rickli C, Graf F (2009) Effects of forests on shallow landslides - case studies in Switzerland. Forest Snow and Landscape Research 82: 33-44

Saaty TL (2000) Fundamentals of decision making and priority theory with the analytic hierarchy process. Rws Publications, Pittsburgh, 6

Saaty TL (2001)The seven pillars of the analytic hierarchy process. In: Köksalan M, Zionts S (eds) Multiple criteria decision making in the new millennium. Springer, Berlin, Heidelberg $15-37$

Saaty TL (2008) Decision making with the analytic hierarchy process. Int J serv Sci 1: 83-98 
Samanta RK, Bhunia GS, Shit PK, Pourghasemi HR (2018) Flood susceptibility mapping using geospatial frequency ratio technique: a case study of Subarnarekha River Basin, India. Model Earth Syst Environ 4:395-408, https://doi.org/10.1007/s40808-018-0427-z

Sarkar S., Kanungo D, Ptra A., Kumar P (2006) Disaster mitigation of debris flow, slope failure, and landslides. GIS-based landslide susceptibility case study in Indian Himalaya. Universal Acadamy Press, Tokyo, Japan 617 - 624

Sarkar S., Rjan Martha T and Roy A (2013) Landslide susceptibility Assessment using information value method in parts of the Darjeeling Himalayas. Geological Society of India $82: 351-362$

Schicker R., Moon V (2012) Comparison of bivariate and multivariate statistical approaches in landslide susceptibility mapping at a regional scale. Geomorphology 161-162: 40-57

Shafizadeh-Moghadam H, Valavi R, Shahabi H, Chapi K, Shirzadi A (2018) Novel forecasting approaches using a combination of machine learning and statistical models for flood susceptibility mapping. J Environ Manage 217: 1-11 https://doi.org/10.1016/j.jenvman.2018.03.089 PMID: 29579536

Tehrany M, Jones S (2017) Evaluating the variations in the flood susceptibility maps accuracies due to the alterations in the type and extent of the flood inventory, ISPRS-Int Arc Photogramm, Remote Sens Spatial Inform Sci 12: 209-214

Tehrany MS, Pradhan B, Jebur MN (2013) Spatial prediction of flood susceptible areas using a rule-based decision tree (DT) and a novel ensemble bivariate and multivariate statistical models in GIS. J Hydrol, 504: 9-79

Tehrany MS, Pradhan B, Jebur MN (2014) Flood susceptibility mapping using a novel ensemble weights-of evidence and support vector machine models in GIS. J Hydrol 512:332343

Tien Bui D, Pradhan, B, Lofman, O, Revhaug, I, Dick, OB (2012) Landslide susceptibility mapping at Hoa Binh province (Vietnam) using an adaptive neuro-fuzzy inference system and GIS. Comput Geosci 45:199-211 
Turoğlu, H, Dölek, I (2011) Floods and their likely impacts on the ecological environment in Bolaman River basin (Ordu, Turkey). RJAS 43(4): 167-173

Wang HB, Wu SR, Shi JS, Li B (2011) Qualitative hazard and risk assessment of landslides: a practical framework for a case study in China. Nat Hazards DOI:10.1007/s11069-011-0008-1

Wubalem Azemeraw*, Meten M (2020) Landslide susceptibility mapping using information value and logistic regression models in Goncha Siso Eneses area, northwestern Ethiopia. SN Applied Sciences, Switzerland AG 2: 807, https://doi.org/10.1007/s42452-020-2563-0

Yesilnacar E, Topal T (2005) Landslide susceptibility mapping: A comparison of logistic regression and neural networks method in a medium scale study, Hendek region (Turkey). Engineering Geology 79:251 - 266

Zhang W, Lu J, Zhang Y (2016) Comprehensive evaluation index system of low carbon road transport based on fuzzy evaluation method. Procedia Eng 37: 659-668

Zhang YS., Javed Igbol, Yae Y (2017) Landslide susceptibility mapping using an integrated model of information value and logistic regression methods in the Bailongjiang watershed, Gansu province, China, Journal of mountain science 14: 249 - 268

Zou Q, Zhou J, Zhou C, Song L, Guo J (2013) Comprehensive flood risk assessment based on set pair analysis-variable fuzzy sets model and fuzzy AHP. Stoch Environ Res Risk Assess 27: $525-546$ 


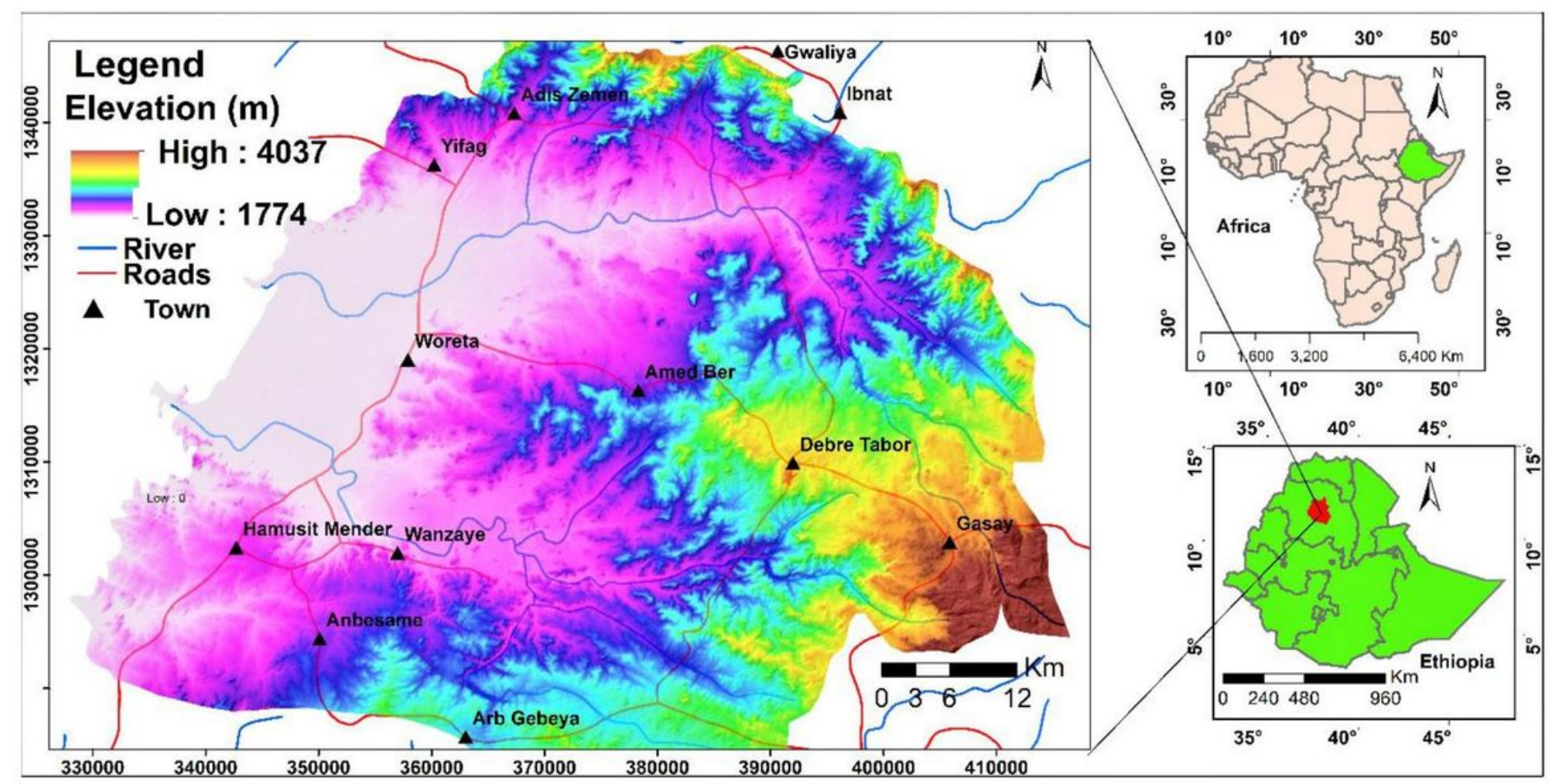

Figure 1

Location Map of the Study Area Note: The designations employed and the presentation of the material on this map do not imply the expression of any opinion whatsoever on the part of Research Square concerning the legal status of any country, territory, city or area or of its authorities, or concerning the delimitation of its frontiers or boundaries. This map has been provided by the authors. 


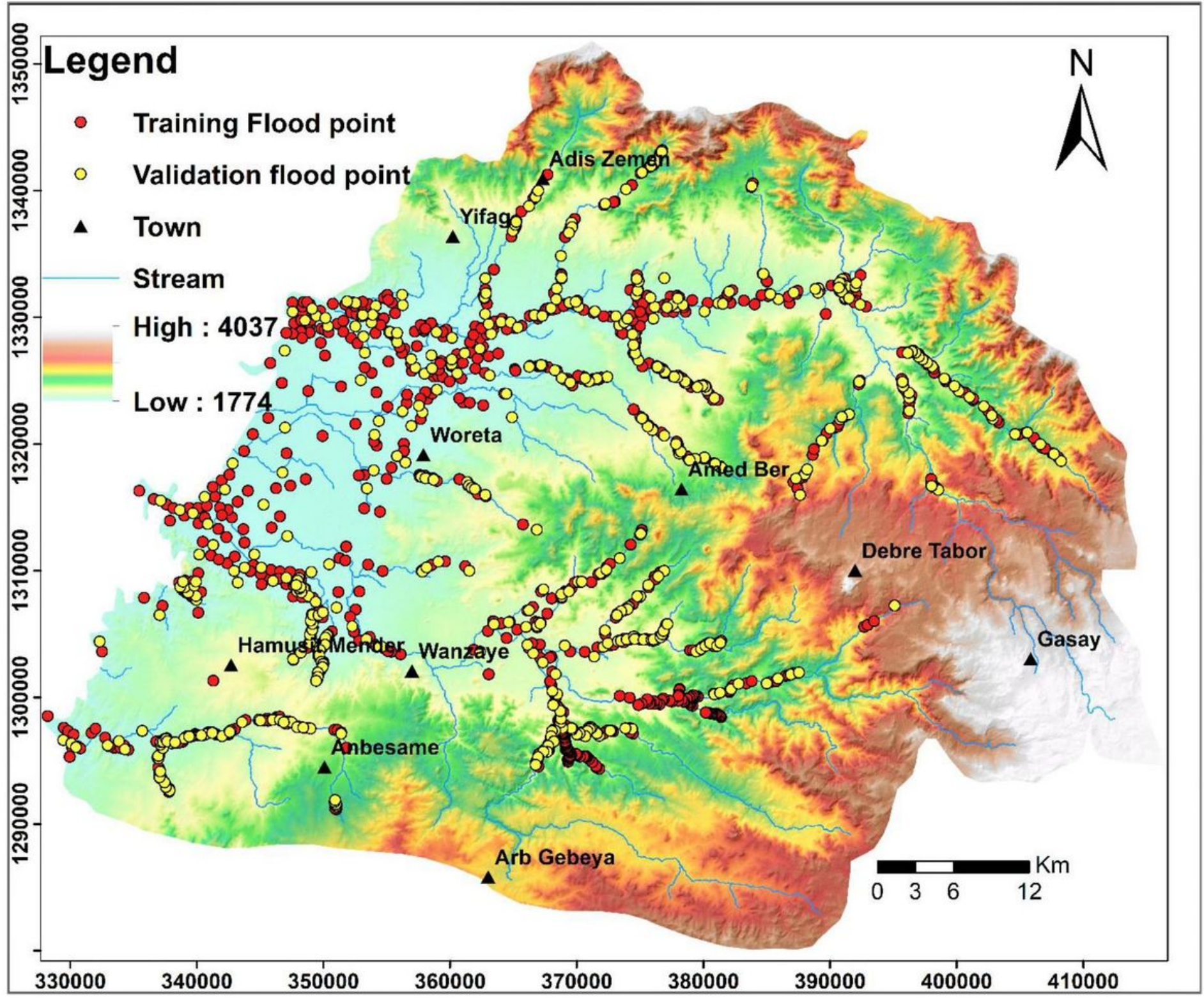

Figure 2

Flood location map Note: The designations employed and the presentation of the material on this map do not imply the expression of any opinion whatsoever on the part of Research Square concerning the legal status of any country, territory, city or area or of its authorities, or concerning the delimitation of its frontiers or boundaries. This map has been provided by the authors. 

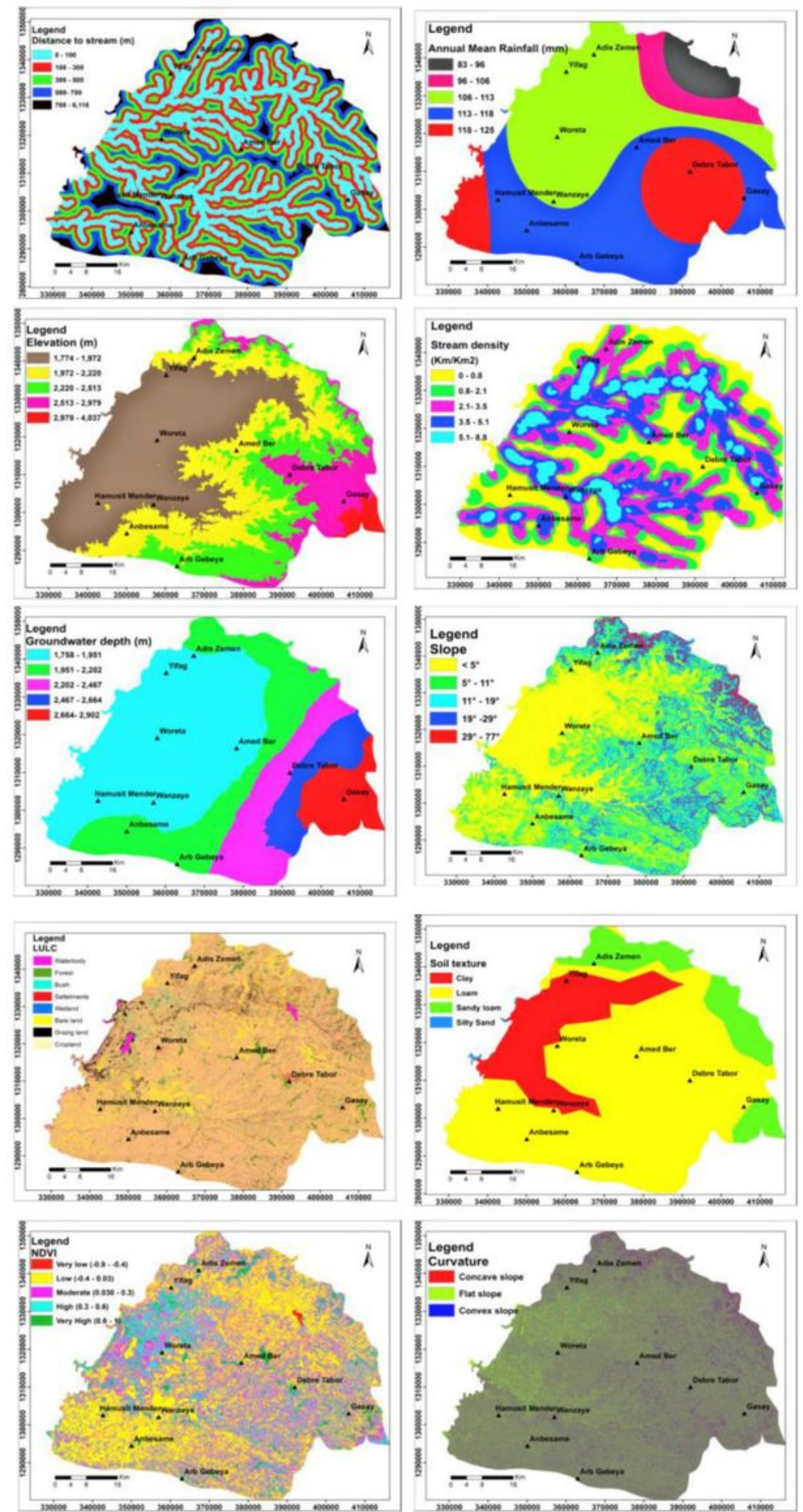

Figure 3

Flood governing factor maps Note: The designations employed and the presentation of the material on this map do not imply the expression of any opinion whatsoever on the part of Research Square concerning the legal status of any country, territory, city or area or of its authorities, or concerning the delimitation of its frontiers or boundaries. This map has been provided by the authors. 


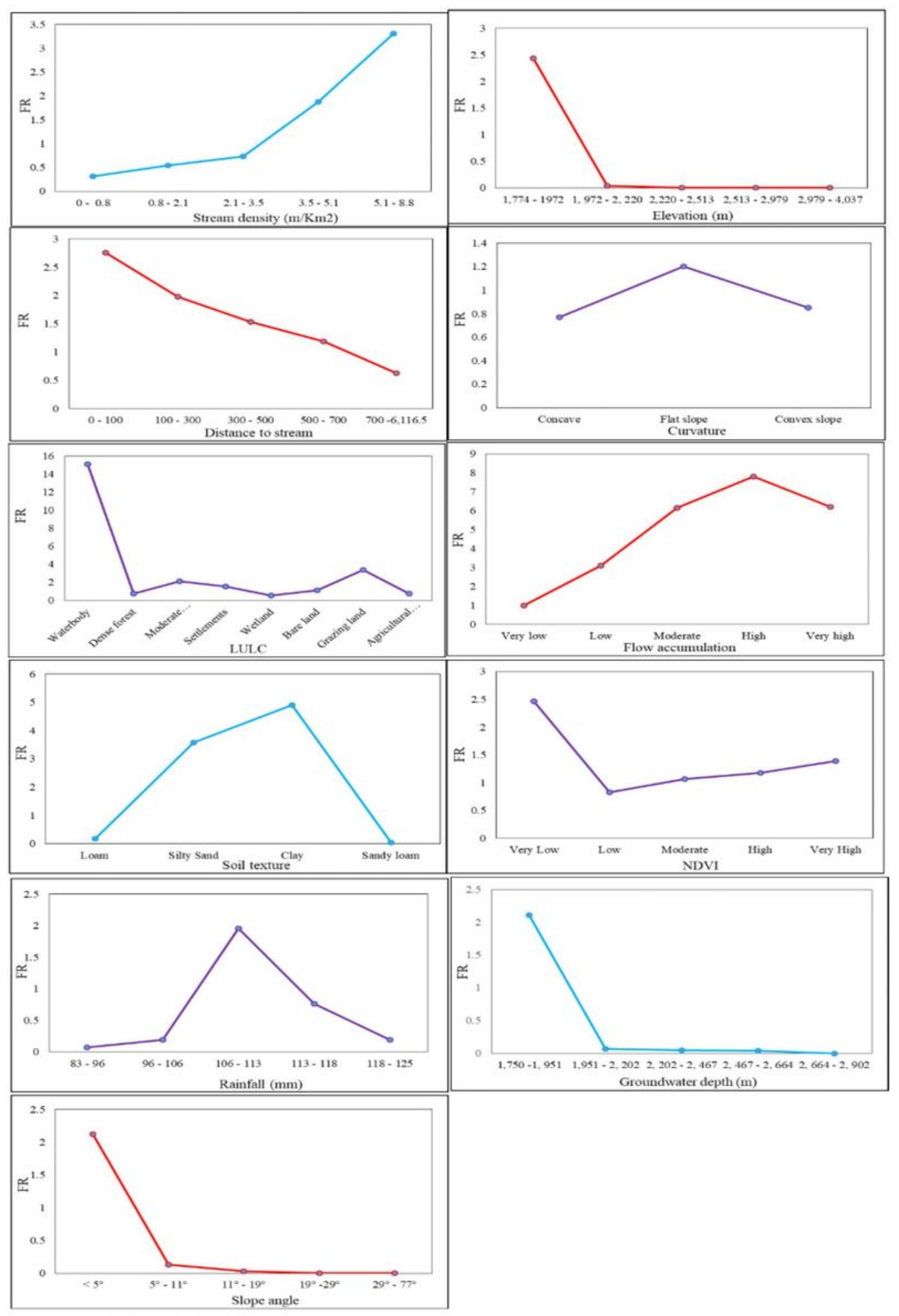

Figure 4

Statistical relationship between flood occurrence and flood driving factors 


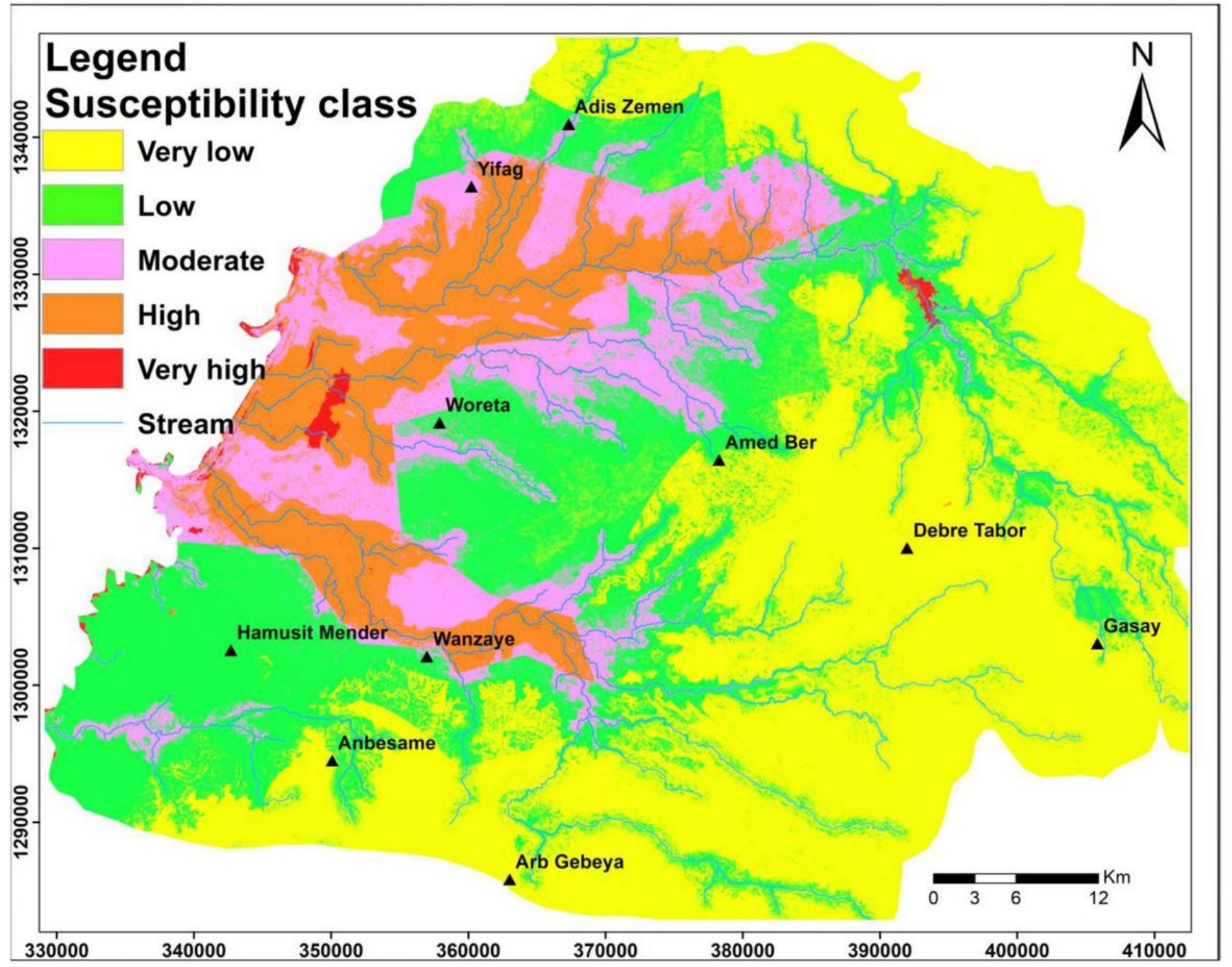

Figure 5

Flood Susceptibility map using the frequency ratio method Note: The designations employed and the presentation of the material on this map do not imply the expression of any opinion whatsoever on the part of Research Square concerning the legal status of any country, territory, city or area or of its authorities, or concerning the delimitation of its frontiers or boundaries. This map has been provided by the authors. 


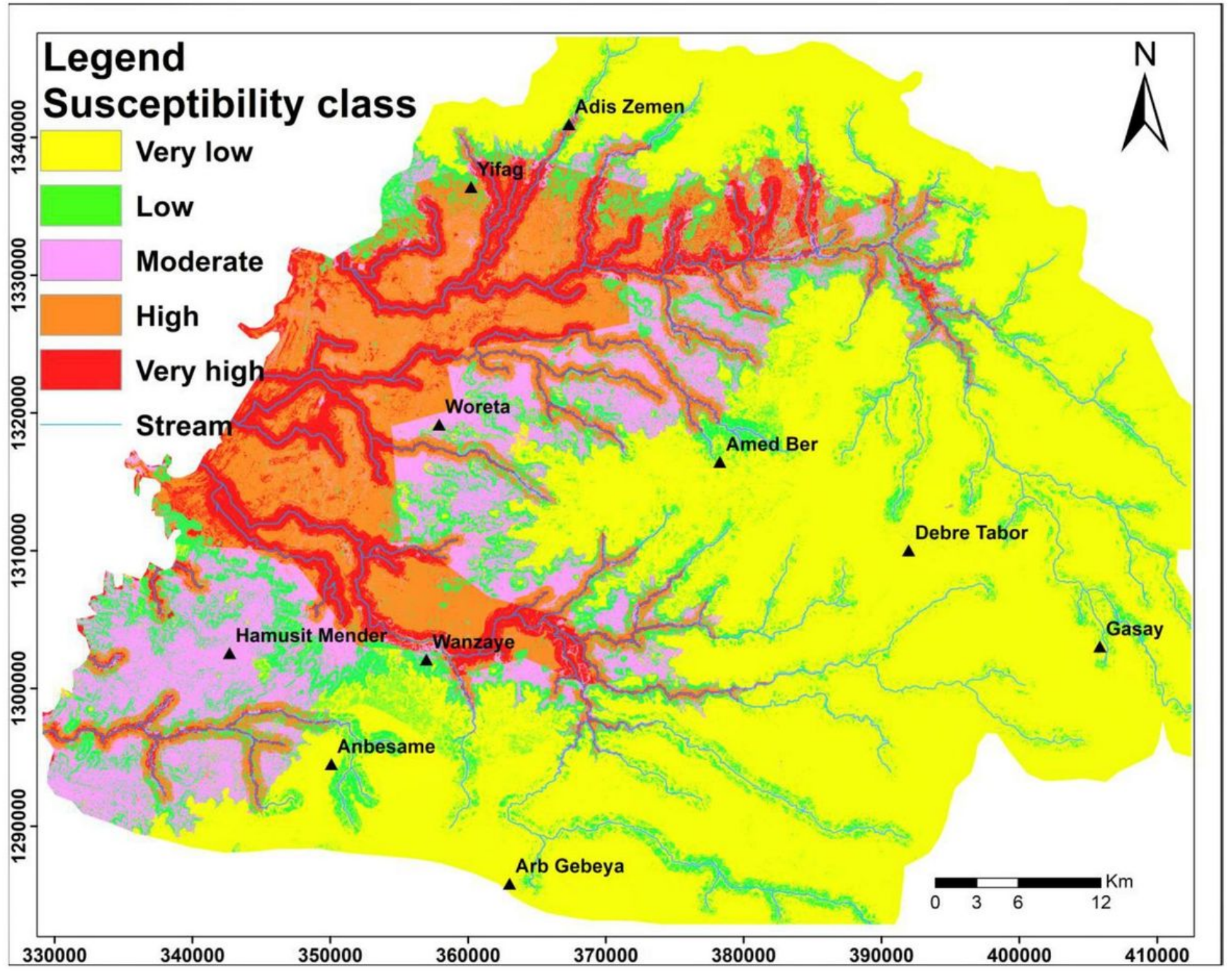

Figure 6

Flood Susceptibility map using information value method Note: The designations employed and the presentation of the material on this map do not imply the expression of any opinion whatsoever on the part of Research Square concerning the legal status of any country, territory, city or area or of its authorities, or concerning the delimitation of its frontiers or boundaries. This map has been provided by the authors. 


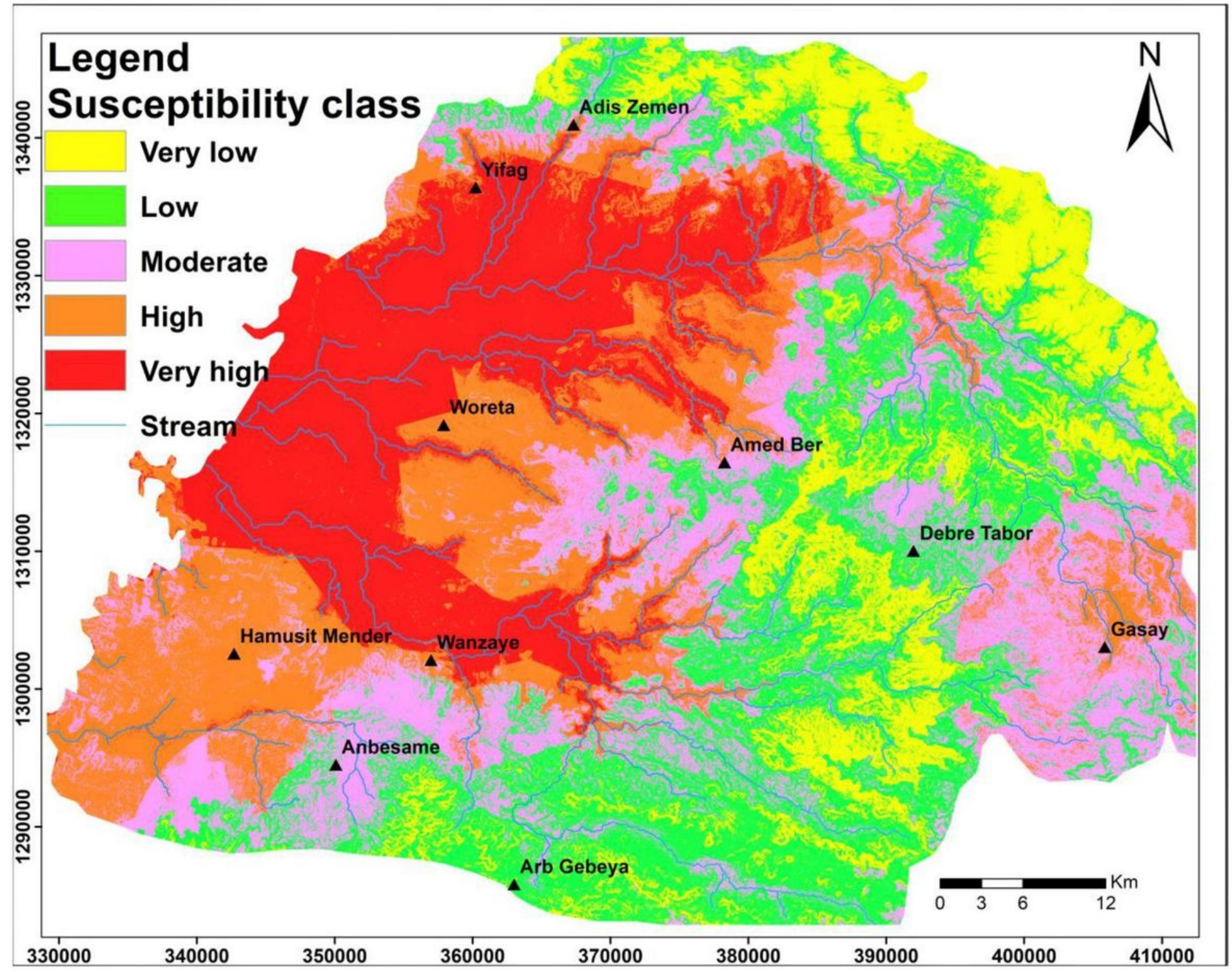

Figure 7

Flood Susceptibility map using the logistic regression method Note: The designations employed and the presentation of the material on this map do not imply the expression of any opinion whatsoever on the part of Research Square concerning the legal status of any country, territory, city or area or of its authorities, or concerning the delimitation of its frontiers or boundaries. This map has been provided by the authors. 


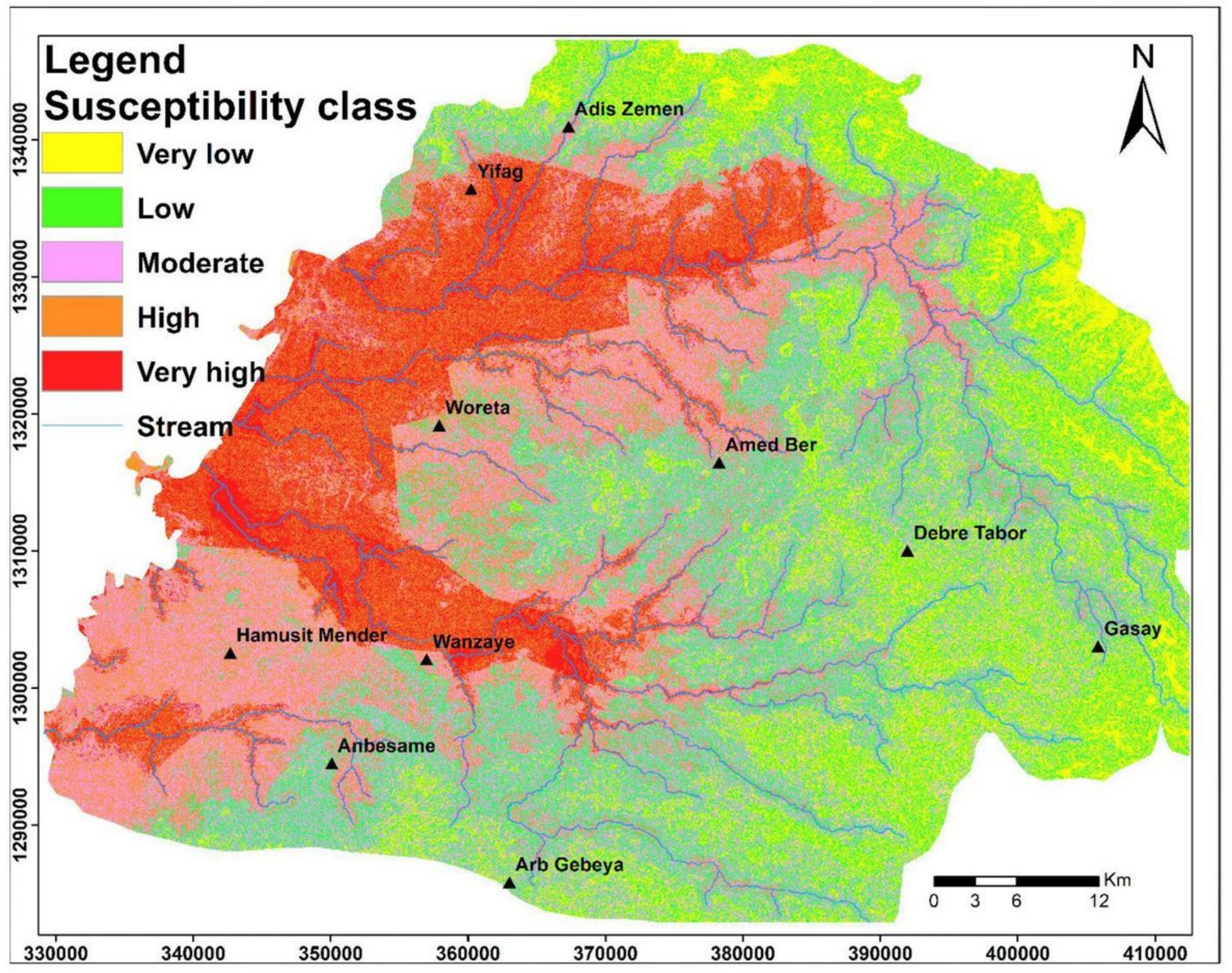

\section{Figure 8}

Flood Susceptibility map using analytical hierarchy process method Note: The designations employed and the presentation of the material on this map do not imply the expression of any opinion whatsoever on the part of Research Square concerning the legal status of any country, territory, city or area or of its authorities, or concerning the delimitation of its frontiers or boundaries. This map has been provided by the authors. 

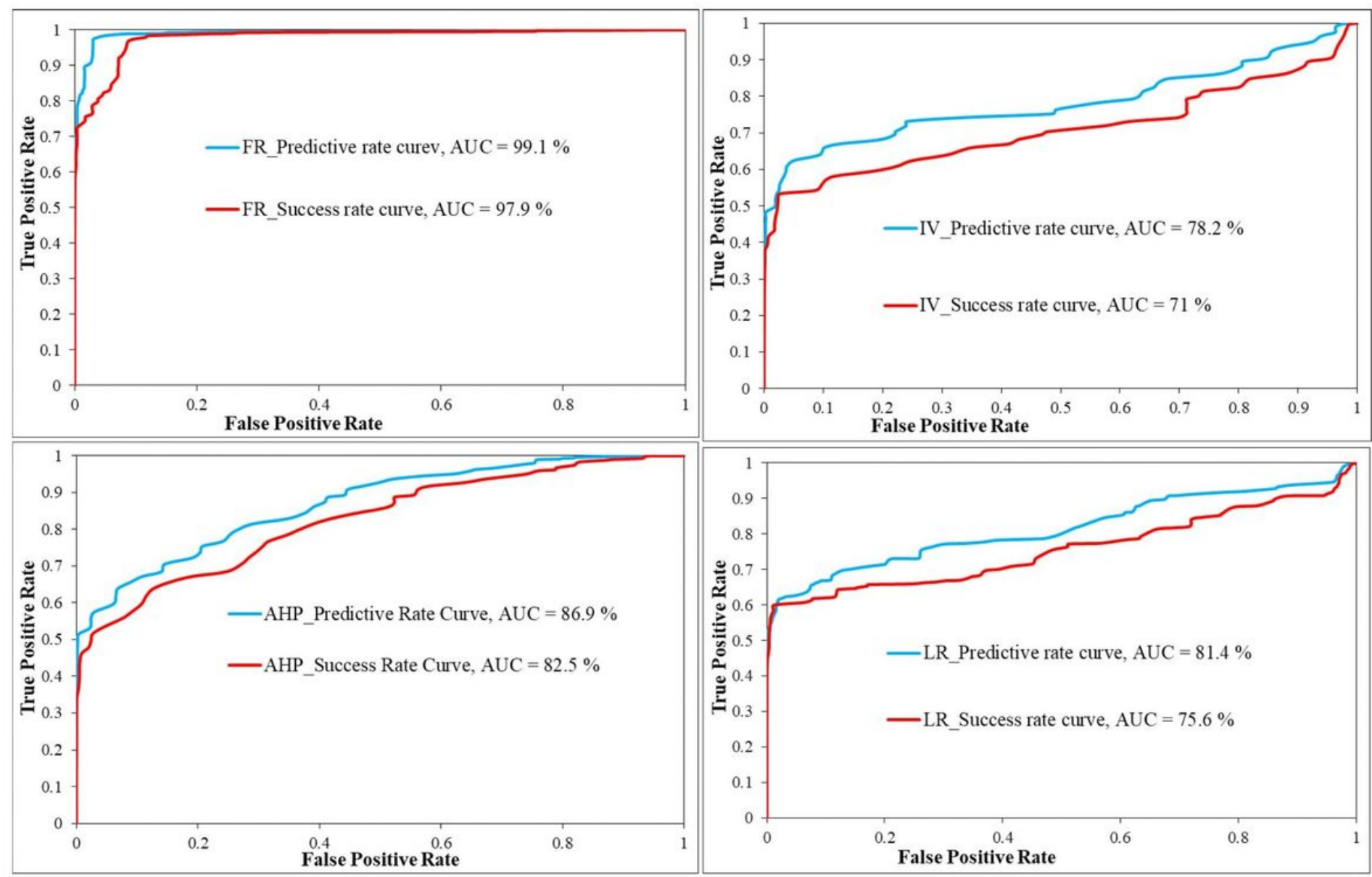

Figure 9

Predictive and success rate curves for IV, LR, FR, and AHP methods 